\title{
Guidelines for Perioperative Care in Bariatric Surgery: Enhanced Recovery After Surgery (ERAS) Society Recommendations
}

\author{
A. Thorell ${ }^{1}$ A. D. MacCormick ${ }^{2,3}$ - S. Awad ${ }^{4,5}$ - N. Reynolds ${ }^{4}$ D. Roulin ${ }^{6}$.

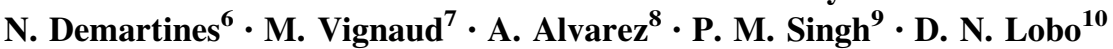

Published online: 4 March 2016

(C) Société Internationale de Chirurgie 2016

\begin{abstract}
Background During the last two decades, an increasing number of bariatric surgical procedures have been performed worldwide. There is no consensus regarding optimal perioperative care in bariatric surgery. This review aims to present such a consensus and to provide graded recommendations for elements in an evidence-based "enhanced" perioperative protocol.

Methods The English-language literature between January 1966 and January 2015 was searched, with particular attention paid to meta-analyses, randomised controlled trials and large prospective cohort studies. Selected studies were examined, reviewed and graded. After critical appraisal of these studies, the group of authors reached a consensus recommendation.

Results Although for some elements, recommendations are extrapolated from non-bariatric settings (mainly colorectal), most recommendations are based on good-quality trials or meta-analyses of good-quality trials.

Conclusions A comprehensive evidence-based consensus was reached and is presented in this review by the enhanced recovery after surgery (ERAS) Society. The guidelines were endorsed by the International Association for Surgical Metabolism and Nutrition (IASMEN) and based on the evidence available in the literature for each of the elements of the multimodal perioperative care pathway for patients undergoing bariatric surgery.
\end{abstract}

A. Thorell

anders.thorell@erstadiakoni.se

1 Karolinska Institutet, Department of Clinical Sciences, Danderyds Hospital \& Department of Surgery, Ersta Hospital, 11691 Stockholm, Sweden

2 Department of Surgery, University of Auckland, Auckland, New Zealand

3 Department of Surgery, Counties Manukau Health, Auckland, New Zealand

4 The East-Midlands Bariatric \& Metabolic Institute, Derby Teaching Hospitals NHS Foundation Trust, Royal Derby Hospital, Derby DE22 3NE, UK

5 School of Clinical Sciences, University of Nottingham, Nottingham NG7 2UH, UK
6 Department of Visceral Surgery, University Hospital CHUV, Lausanne, Switzerland

7 Département d'anesthésie reanimation Service de chirurgie digestive, CHU estaing 1, place Lucie et Raymond Aubrac, Clermont Ferrand, France

8 Department of Anesthesia, Hospital Italiano de Buenos Aires, Buenos Aires University, 1179 Buenos Aires, Argentina

9 Department of Anesthesia, All India Institute of Medical Sciences, New Delhi 110029, India

10 Gastrointestinal Surgery, National Institute for Health Research Nottingham Digestive Diseases Biomedical Research Unit, Nottingham University Hospitals and University of Nottingham, Queen's Medical Centre, Nottingham NG7 2UH, UK 


\section{Introduction}

Bariatric surgery is the most effective treatment for morbid obesity, resulting in sustained weight loss as well as pronounced effects on obesity-related comorbidities. The number of procedures performed worldwide increased from 146,000 to 340,000 between 2003 and 2011, with Roux-en-Y gastric bypass and sleeve gastrectomy accounting for approximately $75 \%$ of all procedures [1]. In the 2013 Scandinavian Registry for Obesity Surgery (SOReg) annual report which included $>8000$ procedures "any complication" and "severe complication" (Clavien grade $>3$ a) [2] within 30 days were reported to be 7 and $3 \%$, respectively [3]. Similar figures were reported from the United Kingdom in 2014 [4].

Enhanced recovery after surgery (ERAS) pathways involve a series of perioperative evidence-based interventions that were developed initially for elective colorectal surgery [5]. ERAS pathways aim to maintain physiological function, enhance mobilisation, reduce pain and facilitate early oral nutrition postoperatively by reducing perioperative surgical stress. The adoption of ERAS pathways has resulted in improved outcome in terms of reduced morbidity, faster recovery and reduced length of hospital stay in dedicated centres [6-11]. Although several of the individual ERAS components have been introduced in the setting of bariatric surgery, there are few reports in the literature on the effects resulting from adoption of complete ERAS pathways.

This article represents an initiative by the ERAS Society (www.erassociety.org) to present a consensus review of optimal perioperative care for bariatric surgery based on best evidence available currently. The guidelines were endorsed by the International Association for Surgical Metabolism and Nutrition (IASMEN; www.iasmen.org) after review of the final version of the manuscript.

\section{Methods}

\section{Literature search}

The authors corresponded by email during the fall of 2013 and the various topics for inclusion were agreed and allocated. The literature search utilised the Medline, Embase and Cochrane databases to identify relevant contributions published between January 1966 and January 2015. Medical Subject Heading (MeSH) terms were used, as were accompanying entry terms for the patient group, interventions and outcomes. Key words included "obesity", "obese", "bariatric", "gastric bypass", "sleeve gastrectomy", "fast track" and "enhanced recovery". Reference lists of all eligible articles were checked for other relevant studies.

\section{Study selection}

Titles and abstracts were screened by individual authors to identify potentially relevant articles. Discrepancies in judgment were resolved by the first and senior authors and through correspondence within the writing group. Particular emphasis was placed on recent publications of good quality (moderate- and high-quality RCTs and large highquality cohort studies as well as systematic reviews and meta-analyses) which were considered for each topic. Retrospective series were included if data of better quality were lacking. Conference proceedings were excluded.

\section{Quality assessment and data analysis}

The methodological quality of the studies was assessed using the Delphi checklist [12]. The strength of evidence and conclusions were assessed and agreed by all authors. Quality of evidence and recommendations were evaluated according to the Grading of Recommendations, Assessment, Development and Evaluation (GRADE) system [13]. Quoting from the GRADE guidelines, the recommendations are given as follows: "Strong recommendations indicate that the panel is confident that the desirable effects of adherence to a recommendation outweigh the undesirable effects". "Weak recommendations indicate that the desirable effects of adherence to a recommendation probably outweigh the undesirable effects, but the panel is less confident". Recommendations are based not only on quality of evidence ("high", "moderate", "low" and "very low") but also on the balance between desirable and undesirable effects and on values and preferences [13]. The latter implies that, in some cases, strong recommendations may be reached from low-quality data and vice versa.

\section{Results: evidence base and recommendations}

The recommendations, evidence and grade of recommendation are summarised in Table 1.

\section{Preoperative interventions}

\section{Preoperative information, education and counselling}

There is little evidence available on the impact of information, education or counselling prior to bariatric surgery. Preoperative information and/or a visit to the ward has been shown to reduce anxiety and improve compliance 
Table 1 ERAS recommendations for (a) preoperative, (b) intraoperative and (c) postoperative care in bariatric surgery

\begin{tabular}{|c|c|c|c|}
\hline Element & Recommendation & Level of evidence & Recommendation grade \\
\hline \multicolumn{4}{|l|}{ (a) } \\
\hline $\begin{array}{l}\text { Preoperative } \\
\text { information, } \\
\text { education and } \\
\text { counselling }\end{array}$ & Patients should receive preoperative counselling & Moderate & Strong \\
\hline $\begin{array}{l}\text { Prehabilitation and } \\
\text { exercise }\end{array}$ & $\begin{array}{l}\text { Although prehabilitation may improve functional recovery, } \\
\text { there are insufficient data in the literature to recommend } \\
\text { prehabilitation before bariatric surgery for the reduction } \\
\text { of complications or length of stay }\end{array}$ & Low & Weak \\
\hline $\begin{array}{l}\text { Smoking and alcohol } \\
\text { cessation }\end{array}$ & $\begin{array}{l}\text { Tobacco smoking should be stopped at least } 4 \text { weeks before } \\
\text { surgery. For patients with a history of alcohol abuse, } \\
\text { abstinence should be strictly adhered to for at least } \\
2 \text { years. Moreover, the risk of relapse (or new onset in } \\
\text { patients without earlier abuse) after gastric bypass should } \\
\text { be acknowledged }\end{array}$ & $\begin{array}{l}\text { Smoking: High } \\
\text { Alcohol: Low (only one } \\
\text { high-quality RCT) }\end{array}$ & Strong \\
\hline $\begin{array}{l}\text { Preoperative weight } \\
\text { loss }\end{array}$ & $\begin{array}{l}\text { Preoperative weight loss should be recommended prior to } \\
\text { bariatric surgery Patients on glucose-lowering drugs } \\
\text { should be aware of the risk of hypoglycaemia }\end{array}$ & $\begin{array}{l}\text { Postoperative } \\
\text { complications: High } \\
\text { Postoperative weight loss: } \\
\text { Low (inconsistency, low } \\
\text { quality) }\end{array}$ & Strong \\
\hline Glucocorticoids & $\begin{array}{l}\text { Eight mg dexamethasone should be administered i.v., } \\
\text { preferably } 90 \text { min prior to induction of anaesthesia for } \\
\text { reduction of PONV as well as inflammatory response }\end{array}$ & $\begin{array}{l}\text { Low (no RCTs in bariatric } \\
\text { surgery) }\end{array}$ & Strong \\
\hline \multirow[t]{3}{*}{ Preoperative fasting } & \multirow{3}{*}{$\begin{array}{l}\text { Obese patients may have clear fluids up to } 2 \text { h and solids up } \\
\text { to } 6 \text { h prior to induction of anaesthesia. Further data are } \\
\text { necessary in diabetic patients with autonomic neuropathy } \\
\text { due to potential risk of aspiration }\end{array}$} & $\begin{array}{l}\text { Non-diabetic obese } \\
\text { patients: High }\end{array}$ & Strong \\
\hline & & $\begin{array}{l}\text { Diabetic patients without } \\
\text { Autonomic neuropathy: } \\
\text { Moderate }\end{array}$ & Weak \\
\hline & & $\begin{array}{l}\text { Diabetic patients with } \\
\text { autonomic neuropathy: } \\
\text { Low }\end{array}$ & Weak \\
\hline Carbohydrate loading & $\begin{array}{l}\text { While preoperative oral carbohydrate conditioning in } \\
\text { patients undergoing major abdominal elective surgery has } \\
\text { been associated with metabolic and clinical benefits, } \\
\text { further data are required in morbidly obese patients. } \\
\text { Similarly, further data are needed on preoperative } \\
\text { carbohydrate conditioning in patients with gastro- } \\
\text { oesophageal reflux who may be at increased risk of } \\
\text { aspiration during anaesthetic induction }\end{array}$ & $\begin{array}{l}\text { Shortened preoperative } \\
\text { fasting (Non-diabetic } \\
\text { obese patients): Low } \\
\text { Diabetic patients without } \\
\text { autonomic neuropathy: } \\
\text { Moderate } \\
\text { Diabetic patients with } \\
\text { autonomic neuropathy: } \\
\text { Low } \\
\text { Preoperative } \\
\text { carbohydrate loading in } \\
\text { obese patients: Low }\end{array}$ & Strong \\
\hline \multicolumn{4}{|l|}{ (b) } \\
\hline $\begin{array}{l}\text { Perioperative fluid } \\
\text { management }\end{array}$ & $\begin{array}{l}\text { Excessive intraoperative fluids are not needed to prevent } \\
\text { rhabdomyolysis and maintain urine output. Functional } \\
\text { parameters, such as stroke volume variation facilitate } \\
\text { goal-directed fluid therapy and avoid intraoperative } \\
\text { hypotension and excessive fluid administration. } \\
\text { Postoperative fluid infusions should be discontinued as } \\
\text { soon as practicable with preference given to use of the } \\
\text { enteral route }\end{array}$ & $\begin{array}{l}\text { Maintenance as opposed } \\
\quad \text { to liberal fluid } \\
\text { regimens: Moderate } \\
\text { Reduce stress response: } \\
\text { Moderate } \\
\text { Open surgery: High } \\
\text { Laparoscopic surgery: } \\
\text { Moderate }\end{array}$ & $\begin{array}{l}\text { Maintenance fluid } \\
\text { regimens: Strong }\end{array}$ \\
\hline PONV & $\begin{array}{l}\text { A multimodal approach to PONV prophylaxis should be } \\
\text { adopted in all patients }\end{array}$ & Low & Strong \\
\hline
\end{tabular}


Table 1 continued

\begin{tabular}{|c|c|c|c|}
\hline Element & Recommendation & Level of evidence & Recommendation grade \\
\hline $\begin{array}{l}\text { Standardised } \\
\text { anaesthetic } \\
\text { protocol }\end{array}$ & $\begin{array}{l}\text { The current evidence does not allow recommendation of } \\
\text { specific anaesthetic agents or techniques }\end{array}$ & Low & Weak \\
\hline \multirow[t]{2}{*}{ Airway management } & $\begin{array}{l}\text { Anaesthetists should be aware of the specific difficulties in } \\
\text { managing bariatric airway }\end{array}$ & Moderate & Strong \\
\hline & $\begin{array}{l}\text { Tracheal intubation remains the reference for airway } \\
\text { management }\end{array}$ & Moderate & Strong \\
\hline \multirow[t]{2}{*}{ Ventilation strategies } & $\begin{array}{l}\text { Lung protective ventilation should be adopted for elective } \\
\text { bariatric surgery }\end{array}$ & Moderate & Strong \\
\hline & $\begin{array}{l}\text { Patient positioning in an anti-Trendelenburg, flexed hip, } \\
\text { anti- or beach chair positioning, particularly in the } \\
\text { absence of pneumoperitoneum improves pulmonary } \\
\text { mechanics and gas exchange }\end{array}$ & Low & Weak \\
\hline \multirow[t]{3}{*}{ Neuromuscular block } & Deep neuromuscular block improves surgical performance & Low & Weak \\
\hline & $\begin{array}{l}\text { Ensuring full reversal of neuromuscular blockade improves } \\
\text { patient recovery }\end{array}$ & Moderate & Strong \\
\hline & $\begin{array}{l}\text { Objective qualitative monitoring of neuromuscular blockade } \\
\text { improves patient recovery }\end{array}$ & Moderate & Strong \\
\hline $\begin{array}{l}\text { Monitoring of } \\
\text { anaesthetic depth }\end{array}$ & $\begin{array}{l}\text { BIS monitoring of anaesthetic depth should be considered } \\
\text { where ETAG monitoring is not employed }\end{array}$ & High & Strong \\
\hline Laparoscopy & $\begin{array}{l}\text { Laparoscopic surgery for bariatric surgery is recommended } \\
\text { whenever expertise is available }\end{array}$ & High & Strong \\
\hline Nasogastric tube & $\begin{array}{l}\text { Routine use of nasogastric tube is not recommended } \\
\text { postoperatively }\end{array}$ & Low & Strong \\
\hline Abdominal drainage & $\begin{array}{l}\text { There is insufficient evidence to recommend routine use of } \\
\text { abdominal drainage }\end{array}$ & Low & Weak \\
\hline \multicolumn{4}{|l|}{ (c) } \\
\hline $\begin{array}{l}\text { Postoperative } \\
\text { analgesia }\end{array}$ & $\begin{array}{l}\text { Multimodal systemic medication and local anaesthetic } \\
\text { infiltration techniques should be combined. Thoracic } \\
\text { epidural analgesia should be considered in laparotomy }\end{array}$ & $\begin{array}{l}\text { Multimodal intravenous } \\
\text { medication, local } \\
\text { anaesthetic infiltration: } \\
\text { High } \\
\text { Epidural analgesia: Very } \\
\text { low }\end{array}$ & $\begin{array}{l}\text { Multimodal intravenous } \\
\text { medication, local } \\
\text { anaesthetic infiltration: } \\
\text { Strong } \\
\text { Epidural analgesia: Weak }\end{array}$ \\
\hline \multirow[t]{2}{*}{ Thromboprophylaxis } & $\begin{array}{l}\text { Thromboprophylaxis should involve mechanical and } \\
\text { pharmacological measures with LMWH. Dosage and } \\
\text { duration of treatment should be individualised }\end{array}$ & $\begin{array}{l}\text { Mechanical measures in } \\
\text { combination with } \\
\text { LMWH: High }\end{array}$ & Strong \\
\hline & & Dosage of LMWH: Low & Weak \\
\hline $\begin{array}{l}\text { Early postoperative } \\
\text { nutrition }\end{array}$ & $\begin{array}{l}\text { Protein intake should be monitored. Iron, vitamin B12 and } \\
\text { calcium supplementation is mandatory } \\
\text { Postoperative glycaemic and lipid control has to be strict in } \\
\text { patients with diabetes }\end{array}$ & $\begin{array}{l}\text { Nutritional } \\
\text { supplementation: } \\
\text { Moderate } \\
\text { Glycaemic control: High }\end{array}$ & Strong \\
\hline \multirow[t]{3}{*}{$\begin{array}{l}\text { Postoperative } \\
\text { oxygenation }\end{array}$} & $\begin{array}{l}\text { Obese patients without OSA, should be supplemented with } \\
\text { oxygen prophylactically in head-elevated or semi-sitting } \\
\text { position in the immediate postoperative period }\end{array}$ & $\begin{array}{l}\text { Prophylactic oxygen } \\
\quad \text { supplementation: Low } \\
\text { (only retrospective data) }\end{array}$ & Strong \\
\hline & & $\begin{array}{l}\text { Positioning in the } \\
\text { postoperative period: } \\
\text { High }\end{array}$ & Strong \\
\hline & $\begin{array}{l}\text { Uncomplicated patients with OSA should receive oxygen } \\
\text { supplementation in a semi-sitting position. Monitoring for } \\
\text { possible increasing frequency of apnoeic episodes should } \\
\text { be diligent. A low threshold for initiation of positive } \\
\text { pressure support must be maintained in the presence of } \\
\text { signs of respiratory distress }\end{array}$ & $\begin{array}{l}\text { High ( } 14 \text { RCTs and } 1 \\
\text { meta-analysis) }\end{array}$ & Strong \\
\hline
\end{tabular}


Table 1 continued

\begin{tabular}{|c|c|c|c|}
\hline Element & Recommendation & Level of evidence & Recommendation grade \\
\hline \multirow[t]{4}{*}{$\begin{array}{l}\text { Non-invasive positive } \\
\text { pressure ventilation }\end{array}$} & $\begin{array}{l}\text { Prophylactic routine postoperative CPAP is not } \\
\text { recommended in obese patients without diagnosed OSA }\end{array}$ & $\begin{array}{l}\text { Moderate (only } \\
\text { retrospective data) }\end{array}$ & $\begin{array}{l}\text { Avoiding routine use of } \\
\text { CPAP: Weak }\end{array}$ \\
\hline & $\begin{array}{l}\text { CPAP therapy should be considered in patients with BMI } \\
>50 \mathrm{~kg} / \mathrm{m}^{2}, \text { severe OSA or oxygen saturation } \leq 90 \% \text { on } \\
\text { oxygen supplementation }\end{array}$ & Low & Strong \\
\hline & $\begin{array}{l}\text { Obese patients with OSA on home CPAP therapy should use } \\
\text { their equipment in the immediate postoperative period }\end{array}$ & $\begin{array}{l}\text { Moderate (Only } \\
\text { retrospective data) }\end{array}$ & Strong \\
\hline & $\begin{array}{l}\text { Patients with Obesity Hypoventilation Syndrome (OHS) } \\
\text { should receive postoperative BiPAP/NIV prophylactically } \\
\text { along with intensive care level monitoring }\end{array}$ & $\begin{array}{l}\text { Low (Only retrospective } \\
\text { data) }\end{array}$ & Strong \\
\hline
\end{tabular}

with postoperative instructions, postoperative recovery, length of stay and long-term outcomes [14-20]. A preoperative psychological intervention has also been shown to reduce fatigue and stress and improve wound healing postoperatively $[21,22]$. Two systematic reviews of patient education [23, 24] evaluated outcomes including biophysical, functional, experiential, cognitive, social, ethical and financial parameters. They identified variable impact of education on outcome but positive results were in a minority. A subsequent RCT of preoperative education in knee arthroplasty has shown a reduction in length of stay [25]. Specific guidelines have recommended preoperative information [26-28].

\section{Prehabilitation and exercise}

Prehabilitation comprises preoperative physical conditioning to improve functional and physiological capacity to enable patients to recover sooner after surgical stress [29, 30]. Improved preoperative physiological status results in an improved postoperative physiological status and faster recovery, decreased postoperative complications and length of stay.

A systematic review evaluated the effects of preoperative exercise therapy on postoperative complications and length of stay in surgery of all types [31]. In patients undergoing cardiac and abdominal surgery, meta-analysis indicated that prehabilitation led to reduced complication rates and length of stay. The applicability of these studies to patients undergoing bariatric surgery is questionable.

A more recent systematic review looked at 8 RCTs investigating the effect of preoperative exercise on cardiorespiratory function and recovery after multiple types of surgery [32] and concluded that there was limited evidence demonstrating physiological improvement with prehabilitation. In addition, there was little correlation between improvement in physiological status and clinical outcomes.

A reanalysis [33] of the data from an original RCT of two prehabilitation methods showed that those who completed prehabilitation prior to colectomy but whose fitness still deteriorated were more likely to suffer complications requiring reoperation or intensive care. A further RCT incorporated 'trimodal prehabilitation' which included nutritional counselling with protein supplementation, anxiety reduction and a moderate exercise program [34] showed no difference in complication rates or length of stay but better functional recovery at 4 and 8 weeks.

Despite prehabilitation being attractive and logical, there is sparse evidence linking improvement of physiological function with preoperative exercise and decreased postoperative complications.

\section{Smoking and alcohol cessation}

In many centres, as well as in most guidelines, drug or alcohol abuse during the preceding 2 years is considered contraindications for bariatric surgery [35].

Tobacco smoking is associated with increased risk of postoperative morbidity and mortality [36], attributed mainly to reduced tissue oxygenation (and consequent wound infections) [37], pulmonary complications [38] and thromboembolism [38]. Several controlled trials have demonstrated that cessation of smoking is associated with marked reductions in postoperative complications [39-42]. The duration of smoking cessation seems to be equally important, with a systematic review and meta-analysis reporting that the treatment effect was significantly larger in trials with smoking cessation of at least 4 weeks [36]. Although not studied specifically in patients undergoing bariatric surgery, there are no data to suggest that either the increased risk associated with smoking or the effect of smoking cessation should be different in this category of patients.

Hazardous drinking, defined as intake of three alcohol equivalents (12 $\mathrm{g}$ ethanol each) or more per day, has long been identified as a risk factor for postoperative complications [43-45]. A large retrospective study comprising $>300000$ patients undergoing elective surgery (including 
bariatric surgery) reported that consumption of $>2$ alcohol equivalents/day within 2 weeks of surgery was an independent predictor of pneumonia, sepsis, wound infection/ disruption and length of hospital stay [44]. Alcohol abstinence for one month has been associated with better outcome after colorectal surgery [46]. ERAS guidelines for colonic surgery, therefore, recommend alcohol cessation 4 weeks prior to surgery. However, due to the need for behavioural changes associated with bariatric surgery in combination with the increased risk of alcohol dependence after gastric bypass surgery [47], 1-2 years of alcohol abstinence is usually considered mandatory in patients with earlier overconsumption. The evidence for this recommendation is, however, still to be established.

\section{Preoperative weight loss}

A preoperative low-calorie diet (LCD, 1000-1200 kcal/d) or very low-calorie diet (VLCD approx. $800 \mathrm{kcal} / \mathrm{d}$ ) for 2-4 weeks is usually recommended in bariatric centres. This has been shown to reduce liver volume by 16-20\% $[48,49]$ and the surgeon's perceived complexity of the procedure [50]. In a systematic review of 11 non-randomised studies, preoperative weight loss was associated with a reduction in postoperative complications $(18.8 \pm 10.6$ vs. $21.4 \pm 13.1 \%, p=0.02)$ [51]. This finding was also confirmed in a multicentre RCT (5.8 vs. $13.2 \%, p=0.04$ ) [50] as well as in a study comprising over 22,000 patients from the Scandinavian Obesity Registry [52]. There are no data from studies evaluating differences between patients with or without diabetes in terms of effect of preoperative weight loss on postoperative complications.

Recent systematic reviews reported mandatory weight loss prior to surgery to be the only factor associated positively with postoperative weight loss $[51,53]$. In a recent registry study including $>9000$ patients undergoing laparoscopic gastric bypass, preoperative weight reduction was associated with improved weight loss after 2 years. Moreover, this effect was more pronounced in patients with high BMI $\left(>45.7 \mathrm{~kg} / \mathrm{m}^{2}\right)[54]$.

In patients with type 2 diabetes on glucose-lowering drugs, low-caloric intake in combination with unchanged medication may induce hypoglycaemia. Evidence-based guidelines for these situations are lacking, but some recommendations are available [55].

\section{Glucocorticoids}

Glucocorticoids have anti-inflammatory properties and have therefore been used in elective surgery to reduce the stress response [56, 57]. They have also been used to reduce postoperative nausea and vomiting (PONV) [58]. In a recent systematic review and meta-analysis [59] of 11 RCTs of moderate quality addressing the effect of glucocorticoids on postoperative outcome, they were found to decrease complication rates and LOS. No effect was found for overall complications or anastomotic leakage in colorectal surgery [59]. A minimum dose of $2.5-5 \mathrm{mg}$ dexamethasone given $90 \mathrm{~min}$ prior to induction of anaesthesia is necessary to achieve the effect on PONV [60-62].

Data from studies including patients undergoing bariatric surgery are relatively sparse. In one retrospective analysis of 2000 consecutive patients undergoing outpatient laparoscopic gastric bypass, a steroid bolus was identified as a predictor of successful discharge within $24 \mathrm{~h}$ [63].

In two meta-analyses, no adverse effects were identified with the use of a single dose of glucocorticoids [59, 64]. As glucocorticoids can cause hyperglycaemia, which is associated with increased postoperative, especially infective, complications [65], blood glucose should be monitored intra- and postoperatively in patients undergoing bariatric surgery, particularly if glucocorticoids are administered.

\section{Preoperative fasting}

Recent studies have demonstrated no differences in residual gastric fluid volume (RGFV), $\mathrm{pH}[66,67]$ or gastric emptying rates following semi-solid meals $[68,69]$ or drinks [70] in obese and lean patients. No differences were found in RGFV and $\mathrm{pH}$ in a randomised study of morbidly obese patients who drank $300 \mathrm{ml}$ of clear fluid $2 \mathrm{~h}$ before induction of anaesthesia, compared with those who fasted from midnight [71, 72]. RGFV and $\mathrm{pH}$ were also similar following an overnight fast in obese diabetic patients (with and without autonomic neuropathy) and non-diabetic controls [72-74]. Presently, anaesthesia societies recommend intake of clear fluids up to $2 \mathrm{~h}$ and solids $6 \mathrm{~h}$ before induction of anaesthesia in healthy [75, 76] and obese [76] patients.

\section{Carbohydrate loading}

Preoperative carbohydrate conditioning, using iso-osmolar drinks ingested $2-3 \mathrm{~h}$ before induction of anaesthesia, attenuated development of postoperative insulin resistance, reduced postoperative nitrogen and protein losses and maintained lean body mass [77]. Recent meta-analyses [78, 79] demonstrated preoperative conditioning using carbohydrate drinks to be associated with significant reduction in length of hospital stay by about 1 day in patients undergoing major abdominal surgery. When 'preoperative' carbohydrate conditioning drinks were administered to patients with type II diabetes (mean BMI $28.6 \mathrm{~kg} / \mathrm{m}^{2}$ ), no differences were noted in gastric emptying times compared 
with healthy subjects [80]. However, postprandial glucose concentrations reached a higher peak and were elevated for longer in patients with diabetes, returning to baseline after $180 \mathrm{~min}$ [80]. In addition, preoperative carbohydrate ingestion did not lead to an increase in aspiration-related complications in patients undergoing laparoscopic gastric bypass [81]. Two further studies have used these drinks in bariatric surgery within an enhanced recovery pathway [82, 83]. In the only randomised study comparing enhanced recovery versus standard care in bariatric patients (laparoscopic sleeve gastrectomy), no differences in overall complications were noted between the groups [82]. However, it was of note that compliance with preoperative carbohydrate conditioning was only $15 \%$ in the enhanced recovery group [82].

\section{Intraoperative interventions}

\section{Perioperative fluid management}

Perioperative fluid management and accurate assessment of volume status in morbidly obese patients are a challenge. Reasons for this include physiological differences, the presence of multiple comorbidities (and associated polypharmacy), inaccuracies associated with use of non-invasive monitoring and higher incidence of rhabdomyolysis (RML) postoperatively [84]. Additionally, liver-shrinking diets, employed for 2-3 weeks preoperatively, may result in acute nutritional, electrolyte and fluid deficits [85]. While total blood volume is increased in obese patients, obese have a reduced blood volume on a volume/weight basis compared with non-obese patients $(50 \mathrm{ml} / \mathrm{kg}$ compared with $75 \mathrm{ml} / \mathrm{kg}$ ) [86].

In bariatric surgery, RML rates of 5-77\% were reported (defined by elevation of serum creatine kinase (CK) of $\geq 1000 \mathrm{IU} / \mathrm{L}$ ) (although $65 \%$ of these procedures were performed by laparotomy) [84]. Of those with RML, the overall incidence of renal failure was $14 \%$ and mortality $3 \%$. Risk factors for RML identified in a meta-analysis were male sex, BMI $>52 \mathrm{~kg} / \mathrm{m}^{2}$ and operation time $>4 \mathrm{~h}$ [84]. Overall, postoperative Acute Renal Failure (ARF, defined by the study authors [87] as a rise in serum creatinine $>1.4 \mathrm{mg} / \mathrm{dL}(>124 \mu \mathrm{mol} / \mathrm{l})$ at any time during the inpatient stay, with an increase of serum creatinine of $>0.3 \mathrm{mg} / \mathrm{dL}(>26 \mu \mathrm{mol} / \mathrm{l})$ from the baseline value during the first postoperative week) has been reported in $2 \%$ of patients undergoing laparoscopic bariatric surgery [87]. Occurrence of intraoperative hypotension was amongst nine predisposing risk factors identified on multivariate analysis. Presence of preoperative renal insufficiency placed patients at greatest risk for postoperative ARF [87].

Few data from RCTs allow guiding perioperative fluid therapy in morbidly obese patients. Present fluid management paradigms are based on studies of liberal versus restrictive strategies in non-obese patients whereby fluid excess or 'imbalance' resulted in worsened outcomes than maintaining 'fluid balance' [88, 89]. In morbidly obese patients, data from non-randomised studies [90-93] support 'liberal' fluid regimens which were associated with reduced occurrence of RML (up to 4-5 L crystalloid during a 2-3 h operation [90]), reduced postoperative nausea and vomiting $(25 \mathrm{ml} / \mathrm{kg}$ which in this study equated to a mean \pm SD $3209 \pm 1123$ versus $2737 \pm 828 \mathrm{ml}$ administered intraoperatively) [92], postoperative ARF (4-5L crystalloid for a $2 \mathrm{~h}$ operation [93]) and shortened hospital stay (7 ml/ $\mathrm{kg} / \mathrm{h}$ which in this study equated to $>1750 \mathrm{ml}$ administered intraoperatively) [94]. In more conservative intraoperative fluid regimens $(15 \mathrm{ml} / \mathrm{kg})$, there were no differences in postoperative RML following laparoscopic bariatric surgery compared to more liberal strategies $(40 \mathrm{ml} / \mathrm{kg}$ ) [95]. No differences in intraoperative urine output were noted when morbidly obese patients were randomised to intraoperative low $(4 \mathrm{ml} / \mathrm{kg} / \mathrm{h})$ vs high $(10 \mathrm{ml} / \mathrm{kg} / \mathrm{h})$ volumes of Ringer's lactate [96]. Functional parameters, such as stroke volume variation (SVV)-guided intraoperative fluid therapy, enabled maintenance of haemodynamic parameters with lower infusion volumes in patients undergoing laparoscopic bariatric surgery [97]. The enteral route for fluid and nutrition should be used preferentially and numerous bariatric series have demonstrated that this is possible on the first postoperative day $[63,98]$.

\section{Anaesthesia}

In this section, information is focused on details of particular relevance in the bariatric setting. For general anaesthetic considerations in gastrointestinal surgery within an ERAS pathway, see Ref. [99].

Postoperative nausea and vomiting prophylaxis Bariatric patients are frequently $<50$ years of age, female and nonsmokers undergoing laparoscopic procedures of more than one hour in duration, and receive postoperative opioid analgesia, all of which are risk factors for PONV [100]. Additionally, a history of PONV or motion sickness, as well as the use of volatile anaesthetic increases the risk of PONV [100].

Recent guidelines for the management of PONV recommend a multimodal approach by reducing the baseline risk with the use of antiemetics according to patient risk factors [101]. Recommended strategies include Propofol for induction and maintenance of anaesthesia, avoidance of volatile anaesthetics, minimisation of intra- and postoperative opioids and avoidance of fluid overload [101]. A recent RCT comparing opioid-free TIVA with volatileopioid anaesthesia in bariatric surgery, reported a 
significantly lower rate and severity of PONV in the opioid-free TIVA group [102]. In addition to this baseline risk reduction, the recommended antiemetics for PONV prophylaxis are 5-hydroxytryptamine receptor antagonists, corticosteroids, butyrophenones, neurokinin-1 receptor antagonists, antihistamines and anticholinergics. The use of a combination of antiemetics in bariatric surgery is supported by a randomised trial demonstrating the superiority of triple combination of haloperidol, dexamethasone and ondansetron over a single or double combination in laparoscopic sleeve gastrectomy [103].

Anaesthetic maintenance Various volatile agents have been compared in the bariatric population. The results are inconsistent, but in general favour the use of shorter acting, lower absorption agents that may offer small advantages in emergence and functional recovery times [104-107].

No prospective comparisons of intravenous versus volatile anaesthetic technique were identified in bariatric surgery. A consistent finding is that early PONV is increased with volatile agents compared to Propofol target controlled infusion. This effect is particularly marked in patients at high risk of PONV [108].

Utilisation of short-acting agents and opioid minimisation within a wider ERAS regimen appears to reduce costs, complication rates and length of stay in other specialities [28]. The current evidence does not allow recommendation of specific anaesthetic agents or techniques in bariatric surgery.

Airway management The airway of bariatric patients can present specific challenges. Bag and mask ventilation has been demonstrated to be difficult in up to $15 \%$ of patients with higher BMI $[109,110]$.

Endotracheal intubation remains the reference standard in obese patients. Correct sizing of endotracheal tube may have impact on micro-aspiration and postoperative complications. Little literature currently exists to recommend routine adoption of supraglottic devices [111].

A Cochrane review was unable to differentiate between the efficacy of direct and indirect fibre-optic mechanisms of tracheal tube placement [112]. However, adoption of a specific ramped position for direct laryngoscopy in the population with high BMI can reduce the incidence of difficulty [113].

Ventilation strategies The effects of intraoperative intermittent positive pressure ventilation (IPPV) regimens on physiological variables are reported in bariatric patients [114-118]. Currently, the translation of these data into effects on postoperative pulmonary complications and outcomes is lacking for the bariatric population.

A 2012 systematic review and meta-analysis on ventilation in bariatric patients did not identify any benefit between volume control and pressure control modes of mandatory ventilation [119]. Concurrent use of positive end expiratory pressure (PEEP) and recruitment improved intraoperative oxygenation and pulmonary mechanics. In a wider surgical population, adoption of the other elements of lung protective ventilation (LPV) was associated with significant reduction in postoperative complications [120].

Patient positioning affects pulmonary function perioperatively [121]. The "beach chair" and "leg flexion position" have been demonstrated to be superior to straight, supine position regardless of Trendelenburg angle. These pulmonary effects are most marked in the absence of the intraoperative pneumoperitoneum [122]. However, they may have negative influence on surgical access with consequent need of increased insufflation pressures [123].

Neuromuscular blockade Deep Block: Higher pressure pneumoperitoneum, to facilitate laparoscopic surgery, can have deleterious cardiovascular effects and increased depth of neuromuscular blockade may improve surgical conditions, without the need to increase insufflation pressure.

Data from small trials in non-bariatric surgery suggest that deep blockade may facilitate manoeuvrability during laparoscopic procedures [124, 125]. Although this may be extrapolated to bariatric procedures, results from prospective trials have yet to be reported [126].

Residual Blockade: The effect of the extent of residual depth of neuromuscular blockade in the recovery period has been studied extensively [127-129], although not specific in bariatric surgery. However, many of the physiological findings may have increased relevance to the bariatric population, e.g. diminished airway/pharyngeal tone, airway diameter, dysfunctional swallow and aspiration defenses.

There is evidence to suggest that a nerve-stimulated train of four (TOF) ratio of 0.9 translates into recovery benefits $[130,131]$. Trials in different healthcare settings have shown an association between residual blockade and post anaesthesia care unit (PACU) pulmonary complications [132, 133]. Reductions in PACU discharge time associated with TOF ratio $>0.9$ have been demonstrated [134]. A higher level of neuromuscular function was also associated with patient perceived satisfaction with the quality of recovery [135].

An early systematic review comparing recovery of neuromuscular function with acetylcholine esterase inhibition versus selective cyclodextrin binding (sugammadex) suggested an equivalent side effect profile [136]. The use of binding agents is supported in bariatric surgery [137-140] where predictability of complete neuromuscular recovery within short time is important. 


\section{Laparoscopy}

Laparoscopic bariatric surgery has rapidly superseded open surgery [141]. Three RCTs including more than 50 patients, compared open with laparoscopic gastric bypass [142-144]. The main findings were significantly shorter hospital stay [142-144] as well as reduced rate of incisional hernia [142, 143] favouring laparoscopy. Further beneficial effects like reduction in intraoperative blood loss [143], diminution of postoperative pain [144] and earlier recovery [143] were also shown. None of these studies found any difference in terms of weight loss. However, due to decreased postoperative adhesions, laparoscopic approach may be associated with increased rates of internal herniation [145, 146].

Higher costs of laparoscopic surgery are compensated for by fewer postoperative complications and shorter hospitalisation time [147]. The use of robotic surgery has also been described in bariatric surgery. A recently published systematic review included results from 2557 patients found similar overall major and minor complications between robotic and laparoscopic groups, but the costs for robotic gastric bypass were higher [148].

\section{Nasogastric tube}

A Cochrane meta-analysis concluded that routine nasogastric intubation following open abdominal surgery should be abandoned in favour of selective use [149]. A subgroup analysis of 9 RCTs including 1085 patients that underwent gastro-duodenal surgery found increased pulmonary complication associated with routine use of postoperative nasogastric tube.

The role of nasogastric tubes in bariatric surgery was specifically addressed in a retrospective cohort study of 1067 gastric bypass patients [150]. There was no difference in complication rates between patients with or without postoperative nasogastric tube. In a meta-analysis of patients with gastrectomy for gastric cancer, time to oral diet was significantly shorter in patients without nasogastric/jejunal decompression [151]. The rate of anastomotic leakage and the number of pulmonary complications were similar.

As routine postoperative nasogastric intubation has not been proven to protect against complications like leakage, and even increases pulmonary infection risk and time to recovery, nasogastric tubes placed during surgery should be removed before reversal of anaesthesia.

\section{Abdominal drainage}

In a systematic review on the role of drainage after Roux-en-Y gastric bypass, the sensitivity of drainage in detecting postoperative leakage varied between 0 and $94 \%$, and the efficacy of drainage for the non-operative treatment of leakage was between 12.5 and $100 \%$ [152]. Only one study reported data about non-operative treatment of leakage without drainage, which was pursued in one out of three patients [153]. However, there are no RCTs evaluating the role and efficacy of prophylactic abdominal drainage following bariatric surgery. A recent retrospective study on laparoscopic Roux-en-Y gastric bypass compared an historical group of 272 patients with routine drain and 483 without [153]. The leakage and reoperation rates were similar.

In one RCT including both subtotal and total gastrectomy with D2 lymph node dissection for gastric cancer, there was no significant difference between the groups with or without drainage in the incidence of intra-abdominal abscess, wound infection or pneumonia [154].

Despite lack of evidence in bariatric surgery, systematic use of abdominal drainage might be unnecessary, as demonstrated in other various types of gastrointestinal surgery [155].

\section{Postoperative interventions}

\section{Postoperative analgesia}

Respiratory function is compromised after bariatric surgery: obesity induces severe restrictive syndrome and lying flat can induce atelectasis. Sedative drugs used during and after anaesthesia promote obstruction of the upper airways which might induce postoperative hypoxaemia [156]. Thus, postoperative analgesia in bariatric surgery is based on two strategies.

Multimodal systemic analgesia Multimodal pain management strategies should be used when possible to reduce the consumption of narcotics [157]. Non-opioid analgesics, such as intravenous acetaminophen (paracetamol) and nonsteroidal anti-inflammatory drugs (NSAIDs) should be used systematically [158]. Dosage should be adapted according to ideal body weight [157]. Other drugs, like pregabalin, have been studied but evidence for its efficacy is still awaited [159]. Current results on the use of dexmedetomidine do not allow recommending its routine use [160]. If opioids become necessary, patient-controlled analgesia with increased refractory period between boluses rather than continuous infusion is recommended, in particular for patients with obstructive sleep apnoea (OSA) [161]. For opioids, the enteral route should be used as early as possible. Surveillance must continue in the postoperative phase [162].

Nerve block and infiltration Wound infiltration with local anaesthetics has been used with success in laparoscopic 
surgery, particularly in cholecystectomy, colorectal and gynaecological surgery, but there are no specific studies in bariatric surgery [163]. RCTs and meta-analyses have demonstrated the safety of local anaesthetic aerosolisation techniques in laparoscopic surgery [164]. It may be combined with pre-incision infiltration [165]. Efficacy of its use has also been demonstrated in bariatric surgery [166] and ropivacaine or levobupivacaine seem to be more effective than short-acting agents, like lidocaine [167]. Recently, it was reported that ultrasound-guided transversus abdominal plane block is feasible and safe in bariatric surgery [168] but data from RCTs comparing this technique with local anaesthetic infiltration are lacking.

Thoracic epidural analgesia (TEA) improves lung function and hastens recovery of spirometric values in obese patients following laparotomy [169] but there is no consensus for laparoscopic surgery. A recent study in laparoscopic colorectal surgery suggested that the use of TEA did not improve outcome or respiratory function, compared with patient-controlled analgesia [170]. A retrospective study in open gastric bypass patients concluded that intravenous morphine was an acceptable strategy for postoperative analgesia, and did not result in more adverse events or poor outcome compared with TEA [171]. Moreover, application of TEA may be complicated in obese patients. Surprisingly, TEA was reported to be associated with a four-fold higher risk of wound infection in patients undergoing open gastric bypass.

\section{Thromboprophylaxis}

In many studies, thromboembolic complications represent the main cause of morbidity and $50 \%$ of mortality after bariatric surgery [172-174]. Risk factors, in addition to obesity itself, include history of venous thromboembolism, increased age, smoking, varicose veins, heart or respiratory failure, OSA, thrombophilia and oestrogen oral contraception [175].

Although not shown to reduce the incidence of fatal pulmonary embolism [176], mechanical methods such as intermittent pneumatic compression or graduated compression stockings should be used. Moreover, early mobilisation and the use of calf-length compression stockings were associated, with a low incidence of deep venous thromboembolism in a study of 280 bariatric patients [177].

Bariatric surgery patients are at least at moderate risk of thromboembolism and, therefore, mechanical methods should be combined with pharmacological prophylaxis. Many studies [172, 178] also in bariatric surgery [179] have compared low molecular weight heparins (LMWH) with unfractionated heparin (UFH), without demonstrating any difference in efficiency or adverse events.
However, LMWH has a number of advantages over UFH, including a more predictable dose response, increased bioavailability and longer plasma half-life after subcutaneous injection, allowing once-daily dosing. LMWH also reduces the risk of heparin-related side effects, such as thrombocytopenia and osteoporosis, with long-term use [180].

The first injection should be administered $8-12 \mathrm{~h}$ after surgery [181]. There are no data supporting an injection twice a day for prophylaxis. However, an increased dose adjusted to BMI (i.e. $6000 \mathrm{u}$ of enoxaparin for BMI $>30 \mathrm{~kg} / \mathrm{m}^{2}, 8000 \mathrm{u}$ for BMI $>40 \mathrm{~kg} / \mathrm{m}^{2}, 10,000 \mathrm{u}$ for BMI $>50 \mathrm{~kg} / \mathrm{m}^{2}$ ) has been shown to be safe without increased risk of bleeding [182-184]. Finally, many studies indicate prolonged risk of thrombotic events, not least due to unpredictable food intake in some patients, encouraging recommendation of 3-4 weeks treatment $[185,186]$. There are no data suggesting that the use of fondaparinux or other new oral anticoagulants should be recommended.

Treatment with vitamin K antagonists should be stopped 5 days before and resumed 12-24 h after surgery in combination with "bridging" LMWH [178].

For patients who cannot receive anticoagulant treatment, the use of retrievable vena cava filters has been evaluated. Many adverse events have been reported and since convincing evidence for its efficacy is lacking [187-189], the use of such devices in current practice is not recommended.

\section{Postoperative nutrition}

Prior to bariatric surgery, all patients should undergo an appropriate nutritional evaluation, including selective micronutrient measurements. In comparison with purely restrictive procedures, more extensive perioperative nutritional evaluations are required for gastric bypass and even more "aggressive" malabsorptive procedures such as biliopancreatic diversion [190].

Early postoperative nutritional care Nutritional and meal planning guidance should be provided to patient and family before bariatric surgery and during the postoperative hospital course and reinforced at subsequent outpatient visits. A clear liquid meal regimen can usually be initiated a couple of hours postoperatively. A consultation should be provided with a dietician and a protocol-derived staged meal progression, based on the type of surgical procedure, should be adhered to.

Patients should adhere to a plan of multiple small meals each day, chewing their food thoroughly without drinking beverages at the same time.

The balanced meal plan should include more than five servings of fruits and vegetables daily for optimal fibre consumption, colonic function and phytochemical intake. 
Protein malnutrition causes an annual hospitalisation rate of $1 \%$ per year after malabsorptive procedures and leads to significant morbidity [191]. Protein intake should average 60-120 g daily. Concentrated sweets should be avoided after any bariatric procedure to reduce caloric intake and in particular after gastric bypass to minimise symptoms of dumping.

Minimal nutritional supplementation includes 1-2 adult multivitamin-mineral supplements containing iron, 1200-1500 mg/d of calcium and vitamin B12 preparation [192].

Fluids should be consumed slowly and in sufficient amounts to maintain adequate hydration (more than $1.5 \mathrm{~L}$ daily) [193]. Clinical and biochemical monitoring is recommended for micro- and macro-nutritional deficiencies, particularly for iron, vitamin B12, calcium and folic acids deficiencies [194].

Management of diabetes mellitus and lipids Postoperative glycaemic control should aim at achieving HbA1c of $62 \mathrm{mmol} / \mathrm{mol}$ or less with fasting blood glucose $\leq 110 \mathrm{mg} /$ dl $(6.1 \mathrm{mmol} / \mathrm{l})$ and postprandial glucose $\leq 180 \mathrm{mg} / \mathrm{dl}$ (10 mmol/l) [195]. Although this is higher compared with usual recommendations by, for example, The American Diabetes Association in non-morbidly obese patients, this degree of glucose control has been shown to be realistic and achievable after bariatric surgery [195]. Physicians and ward nurses should be familiar with glycaemic targets and insulin protocols as well as the use of dextrose-free IV fluids and low-sugar liquid supplements [196]. Obese patients with type 1 diabetes should receive scheduled insulin therapy during their hospital stay. Cessation of insulin treatment is often possible early after bariatric surgery, while liberal continuation of treatment with metformin is usually recommended [197]. Lipid abnormalities should be treated according to the National Cholesterol Educational Program (NCEP) guidelines [198]. Any existing lipid-lowering therapy for LDL-cholesterol and triglyceride values should be continued after surgery if levels remain above desired goals [199, 200].

\section{Postoperative oxygenation}

a) Obese patients without obstructive sleep apnoea (OSA)

Obesity is associated with increased gastric and oesophageal pressures (promoting aspiration), along with reduced FRC and ERV, that increases the work of breathing [201]. After surgery, atelectasis has been found to persist for a longer time in morbidly obese compared with normal weight patients [202]; thus, all obese patients should be considered as high risk irrespective in the presence of OSA.
A Cochrane review evaluated preoperative incentive spirometry and failed to show any benefit in preventing postoperative pulmonary complications [203]. Therefore, routine perioperative use of incentive spirometry for improving oxygenation is not recommended. In open surgery, use of congruent epidural analgesia (epidural insertion site corresponding to dermatomes of surgical incision) with local anaesthetics has been shown to improve postoperative oxygenation [204].

Despite normal pulse oximetry values, immediate postoperative tissue oxygen saturation has been shown to be lower in obese patients [205]. Although tissue oxygen saturation and pulmonary function have been reported to return to normal within the first $24 \mathrm{~h}$ after surgery, there is not enough evidence to recommend a minimum duration of oxygen supplementation. Thus, the use and the duration of postoperative oxygen supplementation need to be individualised. Postoperative positioning in head-elevated, semisitting or prone position (if feasible) further prevents pulmonary atelectasis [202]. Any postoperative sign of insufficient ventilation such as arterial desaturation, tachypnoea, unexplained tachycardia or hypercarbia should prompt the use of positive pressure ventilation.

\section{b) Obese patients with OSA}

There is strong evidence to support a high predictive value of the STOP-BANG questionnaire for preoperative screening of OSA [206]. Patients with moderate to high risk should be considered for positive airway pressure support postoperatively. High vigilance for the need of postoperative positive pressure support is recommended in these patients, in addition to routine oxygen supplementation. These patients should have at least continuous pulse oximetry [207] and respiratory rate monitoring. A metaanalysis concluded that oxygen therapy improves oxygen saturation significantly in patients with OSA [208]. However, it may also increase the duration of apnoea-hypopnoea events and should, therefore, be used carefully. The American Academy of Sleep Medicine recommends careful attention during the first $24 \mathrm{~h}$ after surgery in patients with presumed OSA and also suggests that opioid based patient-controlled analgesia should be avoided [209]. Patients should be discharged from PACU when clinical evaluation is satisfactory and they are fully conscious/oriented with adequate respiratory rate and depth.

\section{Non-invasive positive pressure ventilation}

Non-invasive positive pressure (NIPP) support includes continuous positive airway pressure (CPAP), non-invasive ventilation and bi-level positive airway pressure (BiPAP). Patients with OSA often benefit more from positive pressure support compared with oxygen therapy alone [210]. 
Data from two recent meta-analyses demonstrate that higher $\mathrm{FiO}_{2} \mathrm{~S}$ might actually increase the risk of apnoea/ hypopnoea in morbidly obese patients postoperatively [211]. It is, therefore, recommended that CPAP (beginning from 5 to $7.5 \mathrm{~cm}$ of water) should be used in preference to oxygen therapy alone, in particular in patients with OSA and signs of respiratory deterioration.

Several retrospective analyses evaluating prophylactic CPAP use have not demonstrated a clear benefit in oxygenation [212, 213]. "Super obese" patients (BMI >60 kg/ $\mathrm{m}^{2}$ ), with complications requiring reoperation may be considered for prophylactic CPAP as these patients often need prolonged respiratory support [214]. There is a lack of available evidence to support the use of BiPAP over CPAP in patients without Obesity Hypoventilation Syndrome (OHS, see below) or patients with elevated $\mathrm{pCO}_{2}$ levels. The need of CPAP has been shown to be reduced after laparoscopic compared with open procedures [215].

In terms of requirement for postoperative CPAP/NIV, obese patients can be divided into the following subsets:

\section{a) Obese patients without diagnosed OSA.}

These patients benefit from oxygen therapy (via facemask or nasal cannula), upright positioning and early ambulation. Retrospective analyses have shown that a diagnosis of OSA is often missed in many bariatric surgical patients [216] and this subset of patients is at high risk to develop postoperative complications [217]. In patients with BMI $>35 \mathrm{~kg} / \mathrm{m}^{2}$ the use of nasal CPAP postoperatively might be an alternative due to higher tolerance/compliance, however its therapeutic efficacy may be limited by oral air leaks [218].

b) Patients with OSA-not using preoperative CPAP therapy.

Two subgroups of patients are included in this category: patients with diagnosed OSA without prescribed CPAP, and patients with prescribed CPAP but who do not use it regularly (poor compliance). The severity of OSA could be expected to be worse in the latter group who are candidates needing CPAP in the immediate postoperative period. However, in both groups intraoperative anaesthetic and surgical factors play the most important role for the need for positive pressure ventilatory support due to worsening of OSA. Regional anaesthesia and short-acting anaesthetic drugs should be used [219]. Patient-related factors indicating increased need for NIPP use include moderate to severe OSA [211], male gender, age >50 years, BMI $>60 \mathrm{~kg} / \mathrm{m}^{2}$ [220], pulmonary co-morbidity, open surgery [221] and the need for reoperation [214]. An oxygen saturation below $90 \%$ in the immediate postoperative period is usually defined as hypoxia and indicates need for NIPP [217]. Liberal use of NIPP therapy should, therefore, be adhered to according to the above criteria as well as in the presence of tachypnoea or hypercarbia.

c) Obese patients with OSA on home CPAP therapy.

Compliance with CPAP has been reported to be poor, ranging from 50 to $80 \%$ [222]. However, patients prescribed CPAP habitually should continue their treatment in the postoperative period since it decreases complication rates [223]. Based on data from retrospective studies, slightly higher CPAP values than prescribed for home use may be needed in the postoperative period, due to respiratory inhibitory effects of perioperative narcotics and muscle relaxants [224].

d) Patients with Obesity Hypoventilation Syndrome (OHS) ("Pickwickian syndrome")

OHS is defined as severely obese patients with baseline awake hypoxia and hypercarbia along with raised serum bicarbonate $(>27 \mathrm{mmol} / \mathrm{l})$. Patients with OHS are at high risk of perioperative complications [225]. OHS patients are highly sensitive to opioids irrespective of route of administration (intravenous/central neuraxial) and might present with sustained and life threatening respiratory depression in the postoperative period [226]. Opioid-free anaesthesia with a preference of regional anaesthesia (using local anaesthetics) and the use of minimally invasive procedures is recommended. Prophylactic nasal BiPAP/NIV for 24-48 h postoperatively has been shown to reduce risk of respiratory complications [227]. At least, prophylactic initiation of BiPAP in sitting/semi-sitting position along with intensive monitoring for first $24 \mathrm{~h}$ is recommended in these patients.

\section{Summary and conclusion}

\section{ERAS versus traditional care in bariatric surgery: clinical outcomes}

For bariatric surgery, the literature supporting the use of ERAS is comparatively sparse. Although not defined as a regular ERAS program, McCarty and collaborators reported improved postoperative recovery in 2000 consecutive patients undergoing laparoscopic RYGB with a standardised multimodal program aimed to modify perioperative care [63]. So far, there is one single RCT published in which the use of a standardised ERAS programme in patients undergoing laparoscopic sleeve gastrectomy was compared with "standard care". The authors reported shorter hospital stay with ERAS but no differences in readmission rates, postoperative complications or fatigue scores [82]. In general, most data reporting beneficial effects associated with ERAS are generated from studies 
involving elderly, sometimes medically frail patients, whereas individuals submitted to bariatric surgery are typically younger and more physically fit. Therefore, results from previous studies may not be immediately applicable to bariatric surgery. Morbidity and mortality rates in association with bariatric surgery are relatively low with 3 and $0.04 \%$ for severe complications and mortality, respectively, within 30 days as reported in the Scandinavian Obesity Registry (SOReg) [3], and further reductions in these may be difficult to achieve.

It could be assumed that for some ERAS elements, such as early mobilisation and oral intake, adherence is relatively high in most centres, whereas there may be room for improvement for others, such as postoperative oxygenation and non-invasive positive pressure ventilation. Since the recommendation grade for the use of most of the included ERAS elements for obese individuals undergoing surgery in general is strong, the use of systematic ERAS pathway may have the potential to improve outcomes after bariatric surgery.

\section{Future perspectives and validation}

Data from studies evaluating the effects of ERAS pathways and health costs in patients undergoing bariatric surgery are sparse. Some studies in colorectal [228] and pancreatic [229] surgery reported reduced costs with ERAS, whereas others could not identify any difference [230]. For bariatric surgery and ERAS, reports on quality of life (QOL) are still due and the very few studies reporting data in colorectal surgery have failed to demonstrate any difference [230, 231]. Possible explanations for this might be difficulties associated with randomisation between ERAS and conventional care and/or lack of instruments with sufficient sensitivity to detect any possible improvements in patients' perceived QOL. Nevertheless, QOL and cost will be key elements in evaluating the success of ERAS in the bariatric setting in the future. Implementation and validation of guidelines like the present one are also important factors for improvement of outcome. Therefore, the teams involved in these guidelines will include the recommendations into a web-based ERAS ${ }^{\circledR}$ database for continuous audit and analysis, which will help validate the guidelines in clinical practice.

\section{Comment}

These guidelines represent an effort to provide all caregivers involved in the management of patients undergoing bariatric surgery with an overview of the current literature. Surgical and anaesthesiological practice is continuously developing, which means that recommendations need to be challenged and updated, probably within 3- to 5-years interval. It might seem to the reader that the level of evidence for many of the elements is surprisingly low. However, it should be acknowledged that this reflects the current situation in most areas of modern medicine in general and not least within surgical practice.

Acknowledgments The authors thank Professor Karem Slim, Service de Chirurgie Digestive \& Unité de Chirurgie Ambulatories, CHU Estaing, Clermont-Ferrand, France for his preliminary work on the manuscript.

Funding Financial support was provided through the Erling-Persson Family Foundation and through the regional agreement on medical training and clinical research between Stockholm County Council and Karolinska Institutet (AT). The ERAS society has support from Nutricia Research via an unrestricted educational grant.

\section{Compliance with Ethical Standards}

Conflict of Interests AT and MV have no conflicts of interest to declare. ADM has no direct conflicts of interest to declare. He has received speakers' honoraria from Covidien. DR has no direct conflict of interest to declare. SA has no direct conflicts of interest to declare. He has received speakers' honoraria and consultation fees from Fischer \& Paykel Healthcare, Merck Sharp \& Dohme and BBraun; unrestricted educational grants from Fresenius Kabi, Nestle Nutrition, Covidien, Ethicon EndoSurgery, Merck Sharp \& Dohme, Fischer \& Paykel Healthcare, GORE and BBraun. He has also completed a bariatric fellowship funded via an educational grant from Ethicon EndoSurgery (paid to the institution). ND has no direct conflicts of interest to declare. He has received unrestricted grants and speakers' honoraria from Johnson \& Johnson, Nestlé and from MSD. DNL has no direct conflicts of interest to declare. He has received unrestricted grants and speakers' honoraria from Fresenius Kabi, BBraun, Nutricia and Baxter Healthcare.

\section{References}

1. Buchwald H, Oien DM (2013) Metabolic/bariatric surgery worldwide 2011. Obes Surg 23:427-436

2. Dindo D, Demartines N, Clavien PA (2004) Classification of surgical complications: a new proposal with evaluation in a cohort of 6336 patients and results of a survey. Ann Surg 240:205-213

3. SOReg-Scandinavian Obesity Surgery registry Annual Report (2013), Annual Report http://ucr.uu.se/soreg

4. National Bariatric Surgery Registry of the British Obesity \& Metabolic Sugery Society (2014). http://nbsr.co.uk/2014-report

5. Fearon KC, Ljungqvist O, Von Meyenfeldt $M$ et al (2005) Enhanced recovery after surgery: a consensus review of clinical care for patients undergoing colonic resection. Clin Nutr 24:466-477

6. Basse L, Hjort Jakobsen D, Billesbolle P et al (2000) A clinical pathway to accelerate recovery after colonic resection. Ann Surg 232:51-57

7. Basse L, Raskov HH, Hjort Jakobsen D et al (2002) Accelerated postoperative recovery programme after colonic resection improves physical performance, pulmonary function and body composition. Br J Surg 89:446-453

8. Wind J, Hofland J, Preckel B et al (2006) Perioperative strategy in colonic surgery; LAparoscopy and/or FAst track multimodal management versus standard care (LAFA trial). BMC Surg 6:16 
9. Khoo CK, Vickery CJ, Forsyth $\mathrm{N}$ et al (2007) A prospective randomized controlled trial of multimodal perioperative management protocol in patients undergoing elective colorectal resection for cancer. Ann Surg 245:867-872

10. Serclova Z, Dytrych P, Marvan J et al (2009) Fast-track in open intestinal surgery: prospective randomized study (Clinical Trials Gov Identifier no. NCT00123456). Clin Nutr 28:618-624

11. Muller S, Zalunardo MP, Hubner M et al (2009) A fast-track program reduces complications and length of hospital stay after open colonic surgery. Gastroenterology 136:842-847

12. Verhagen AP, de Vet HC, de Bie RA et al (1998) The Delphi list: a criteria list for quality assessment of randomized clinical trials for conducting systematic reviews developed by Delphi consensus. J Clin Epidemiol 51:1235-1241

13. Guyatt GH, Oxman AD, Vist GE et al (2008) GRADE: an emerging consensus on rating quality of evidence and strength of recommendations. BMJ 336:924-926

14. Kiecolt-Glaser J, Page G, Marucha P et al (1998) Psychological influences on surgical recovery. Perspectives from psychoneuroimmunology. Am Psychol 53:1209-1218

15. Hathaway D (1986) Effect of preoperative instruction on postoperative outcomes: a meta-analysis. Nurs Res 35:269-275

16. Devine EC, Cook TD (1983) A meta-analytic analysis of effects of psychoeducational interventions on length of postsurgical hospital stay. Nurs Res 32:267-274

17. Egbert LD, Battit GE, Welch CE et al (1964) Reduction of postoperative pain by encouragement and instruction of patients. A study of doctor-patient rapport. N Engl J Med 270:825-827

18. Disbrow EA, Bennett HL, Owings JT (1993) Effect of preoperative suggestion on postoperative gastrointestinal motility. West J Med 158:488-492

19. Halaszynski TM, Juda R, Silverman DG (2004) Optimizing postoperative outcomes with efficient preoperative assessment and management. Crit Care Med 32:S76-S86

20. Forster AJ, Clark HD, Menard A et al (2005) Effect of a nurse team coordinator on outcomes for hospitalized medicine patients. Am J Med 118:1148-1153

21. Kahokehr A, Broadbent E, Wheeler BR et al (2012) The effect of perioperative psychological intervention on fatigue after laparoscopic cholecystectomy: a randomized controlled trial. Surg Endosc 26:1730-1736

22. Broadbent E, Kahokehr A, Booth RJ et al (2012) A brief relaxation intervention reduces stress and improves surgical wound healing response: a randomised trial. Brain Behav Immun 26:212-217

23. Johansson K, Salantera S, Heikkinen K et al (2004) Surgical patient education: assessing the interventions and exploring the outcomes from experimental and quasi-experimental studies from 1990 to 2003. Clin Eff Nurs 8:81-92

24. Ronco M, Iona L, Fabbro C et al (2012) Patient education outcomes in surgery: a systematic review from 2004 to 2010. Int J Evid Based Healthe 10:309-323

25. Stacey D, Taljaard M, Dervin G et al (2015) Impact of patient decision aids on appropriate and timely access to hip or knee arthroplasty for osteoarthritis: a randomized controlled trial. Osteoarthr Cartil 24(1):99-107

26. Committee SG (2008) SAGES guideline for clinical application of laparoscopic bariatric surgery. Surg Endosc 22:2281-2300

27. Mechanick J, Kushner R, Sugerman H et al (2009) American Association of Clinical Endcrinoliogists, The Obesity Society, and American Society for Metabolic and Bariatric Surgery medical guidelines for clinical practice for the perioperative nutritional, metabolic, and nonsurgical support of the bariatric surgery patient. Obesity 17:S1-S70

28. Gustafsson UO, Scott MJ, Schwenk W et al (2012) Guidelines for perioperative care in elective colonic surgery: enhanced recovery after surgery $\left(\right.$ ERAS $\left.^{\circledR}\right)$ society recommendations. Clin Nutr 31:783-800

29. Carli F, Zavorsky GS (2005) Optimizing functional exercise capacity in the elderly surgical population. Curr Opin Clin Nutr Metab Care 8:23-32

30. Topp R, Swank AM, Quesada PM et al (2009) The effect of prehabilitation exercise on strength and functioning after total knee arthroplasty. PM R 1:729-735

31. Valkenet K, Port I, Dronkers J et al (2011) The effects of preoperative exercise therapy on postoperative outcome: a systematic review. Clin Rehabil 25:99-111

32. Lemanu DP, Singh PP, MacCormick AD et al (2013) Effect of preoperative exercise on cardiorespiratory function and recovery after surgery: a systematic review. World J Surg 37:711-720. doi:10.1007/s00268-012-1886-4

33. Carver TE, Mayo N, Andersen RE et al (2011) Pilot investigation to evaluate changes in exercise capacity following a prehabilitation intervention among seriously obese patients awaiting bariatric surgery. Can J Diabet 35:149

34. Carli F, Charlebois P, Stein B et al (2010) Randomized clinical trial of prehabilitation in colorectal surgery. $\mathrm{Br} \mathrm{J}$ Surg 97:1187-1197

35. Fried M, Hainer V, Basdevant A et al (2007) Interdisciplinary European guidelines for surgery for severe (morbid) obesity. Obes Surg 17:260-270

36. Mills E, Eyawo O, Lockhart I et al (2011) Smoking cessation reduces postoperative complications: a systematic review and meta-analysis. Am J Med 124(144-154):e8

37. Sorensen LT, Karlsmark T, Gottrup F (2003) Abstinence from smoking reduces incisional wound infection: a randomized controlled trial. Ann Surg 238:1-5

38. Gourgiotis S, Aloizos S, Gakis C et al (2011) Platypnea-orthodeoxia due to fat embolism. Int J Surg Case Rep 2:147-149

39. Moller AM, Villebro N, Pedersen T et al (2002) Effect of preoperative smoking intervention on postoperative complications: a randomised clinical trial. Lancet 359:114-117

40. Levin L, Herzberg R, Dolev E et al (2004) Smoking and complications of onlay bone grafts and sinus lift operations. Int $\mathrm{J}$ Oral Maxillofac Implants 19:369-373

41. Myles PS, Leslie K, Angliss M et al (2004) Effectiveness of bupropion as an aid to stopping smoking before elective surgery: a randomised controlled trial. Anaesthesia 59:1053-1058

42. Warner DO, Patten CA, Ames SC et al (2005) Effect of nicotine replacement therapy on stress and smoking behavior in surgical patients. Anesthesiology 102:1138-1146

43. Tonnesen H, Petersen KR, Hojgaard L et al (1992) Postoperative morbidity among symptom-free alcohol misusers. Lancet 340:334-337

44. Nath B, Li Y, Carroll JE et al (2010) Alcohol exposure as a risk factor for adverse outcomes in elective surgery. J Gastrointest Surg 14:1732-1741

45. Tonnesen H, Kehlet H (1999) Preoperative alcoholism and postoperative morbidity. Br J Surg 86:869-874

46. Tonnesen H, Rosenberg J, Nielsen HJ et al (1999) Effect of preoperative abstinence on poor postoperative outcome in alcohol misusers: randomised controlled trial. BMJ 318:1311-1316

47. Ostlund MP, Backman O, Marsk R et al (2013) Increased admission for alcohol dependence after gastric bypass surgery compared with restrictive bariatric surgery. JAMA Surg 148:374-377

48. Edholm D, Kullberg J, Haenni A et al (2011) Preoperative 4-week low-calorie diet reduces liver volume and intrahepatic fat, and facilitates laparoscopic gastric bypass in morbidly obese. Obes Surg 21:345-350

49. Colles SL, Dixon JB, Marks P et al (2006) Preoperative weight loss with a very-low-energy diet: quantitation of changes in liver 
and abdominal fat by serial imaging. Am J Clin Nutr 84:304-311

50. Van Nieuwenhove Y, Dambrauskas Z, Campillo-Soto A et al (2011) Preoperative very low-calorie diet and operative outcome after laparoscopic gastric bypass: a randomized multicenter study. Arch Surg 146:1300-1305

51. Cassie S, Menezes C, Birch DW et al (2011) Effect of preoperative weight loss in bariatric surgical patients: a systematic review. Surg Obes Relat Dis 7:760-767 discussion 767

52. Anderin C, Gustafsson UO, Heijbel N et al (2015) Weight loss before bariatric surgery and postoperative complications: data from the Scandinavian Obesity Registry (SOReg). Ann Surg 261:909-913

53. Livhits M, Mercado C, Yermilov I et al (2009) Does weight loss immediately before bariatric surgery improve outcomes: a systematic review. Surg Obes Relat Dis 5:713-721

54. Gerber P, Anderin C, Gustafsson UO et al (2015) Weight loss immediately prior to gastric bypass and postoperative weight change. Surg Obes Relat Dis. doi:10.1016/j.soard.2015.08.519

55. Thorell A, Hagstrom-Toft E (2012) Treatment of diabetes prior to and after bariatric surgery. J Diabetes Sci Technol 6:1226-1232

56. Barnes PJ (1998) Anti-inflammatory actions of glucocorticoids: molecular mechanisms. Clin Sci (Lond) 94:557-572

57. Sapolsky RM, Romero LM, Munck AU (2000) How do glucocorticoids influence stress responses? Integrating permissive, suppressive, stimulatory, and preparative actions. Endocr Rev 21:55-89

58. Henzi I, Walder B, Tramer MR (2000) Dexamethasone for the prevention of postoperative nausea and vomiting: a quantitative systematic review. Anesth Analg 90:186-194

59. Srinivasa S, Kahokehr AA, Yu TC et al (2011) Preoperative glucocorticoid use in major abdominal surgery: systematic review and meta-analysis of randomized trials. Ann Surg 254:183-191

60. Liu K, Hsu CC, Chia YY (1999) The effective dose of dexamethasone for antiemesis after major gynecological surgery. Anesth Analg 89:1316-1318

61. Wang JJ, Ho ST, Lee SC et al (2000) The use of dexamethasone for preventing postoperative nausea and vomiting in females undergoing thyroidectomy: a dose-ranging study. Anesth Analg 91:1404-1407

62. Wang JJ, Ho ST, Wong CS et al (2001) Dexamethasone prophylaxis of nausea and vomiting after epidural morphine for post-Cesarean analgesia. Can J Anaesth 48:185-190

63. McCarty TM, Arnold DT, Lamont JP et al (2005) Optimizing outcomes in bariatric surgery: outpatient laparoscopic gastric bypass. Ann Surg 242:494-498 discussion 498-501

64. Sauerland S, Nagelschmidt M, Mallmann P et al (2000) Risks and benefits of preoperative high dose methylprednisolone in surgical patients: a systematic review. Drug Saf 23:449-461

65. van den Berghe G, Wouters P, Weekers F et al (2001) Intensive insulin therapy in critically ill patients. $\mathrm{N}$ Engl $\mathrm{J}$ Med 345:1359-1367

66. Harter RL, Kelly WB, Kramer MG et al (1998) A comparison of the volume and $\mathrm{pH}$ of gastric contents of obese and lean surgical patients. Anesth Analg 86:147-152

67. Juvin P, Fevre G, Merouche M et al (2001) Gastric residue is not more copious in obese patients. Anesth Analg 93:1621-1622 table of contents

68. Cardoso-Junior A, Coelho LG, Savassi-Rocha PR et al (2007) Gastric emptying of solids and semi-solids in morbidly obese and non-obese subjects: an assessment using the 13C-octanoic acid and 13C-acetic acid breath tests. Obes Surg 17:236-241

69. Buchholz V, Berkenstadt H, Goitein D et al (2013) Gastric emptying is not prolonged in obese patients. Surg Obes Relat Dis 9:714-717
70. Seimon RV, Brennan IM, Russo A et al (2013) Gastric emptying, mouth-to-cecum transit, and glycemic, insulin, incretin, and energy intake responses to a mixed-nutrient liquid in lean, overweight, and obese males. Am J Physiol Endocrinol Metab 304:E294-E300

71. Maltby JR, Pytka S, Watson NC et al (2004) Drinking $300 \mathrm{~mL}$ of clear fluid two hours before surgery has no effect on gastric fluid volume and $\mathrm{pH}$ in fasting and non-fasting obese patients. Can J Anaesth 51:111-115

72. Maltby JR (2006) Fasting from midnight - the history behind the dogma. Best Pract Res Clin Anaesthesiol 20:363-378

73. Ishihara H, Singh H, Giesecke AH (1994) Relationship between diabetic autonomic neuropathy and gastric contents. Anesth Analg 78:943-947

74. Bertin E, Schneider N, Abdelli N et al (2001) Gastric emptying is accelerated in obese type 2 diabetic patients without autonomic neuropathy. Diabetes Metab 27:357-364

75. The American Society of Anesthesiologist Task Force on Preoperative Fasting (1999) Practice guidelines for preoperative fasting and the use of pharmacologic agents to reduce the risk of pulmonary aspiration: application to healthy patients undergoing elective procedures: a report by the American Society of Anesthesiologist Task Force on Preoperative Fasting. Anesthesiology 90:896-905

76. Smith I, Kranke P, Murat I et al (2011) Perioperative fasting in adults and children: guidelines from the European Society of Anaesthesiology. Eur J Anaesthesiol 28:556-569

77. Ljungqvist O (2012) Jonathan E. Rhoads lecture 2011: insulin resistance and enhanced recovery after surgery. JPEN J Parenter Enteral Nutr 36:389-398

78. Awad S, Varadhan KK, Ljungqvist $O$ et al (2013) A metaanalysis of randomised controlled trials on preoperative oral carbohydrate treatment in elective surgery. Clin Nutr 32:34-44

79. Smith MD, McCall J, Plank L et al (2014) Preoperative carbohydrate treatment for enhancing recovery after elective surgery. Cochrane Database Syst Rev 8:Cd009161

80. Gustafsson UO, Nygren J, Thorell A et al (2008) Pre-operative carbohydrate loading may be used in type 2 diabetes patients. Acta Anaesthesiol Scand 52:946-951

81. Azagury DE, Ris F, Pichard C et al (2015) Does perioperative nutrition and oral carbohydrate load sustainably preserve muscle mass after bariatric surgery? A randomized control trial. Surg Obes Relat Dis 11:920-926

82. Lemanu DP, Singh PP, Berridge K et al (2013) Randomized clinical trial of enhanced recovery versus standard care after laparoscopic sleeve gastrectomy. Br J Surg 100:482-489

83. Ronellenfitsch U, Schwarzbach M, Kring A et al (2012) The effect of clinical pathways for bariatric surgery on perioperative quality of care. Obes Surg 22:732-739

84. Chakravartty S, Sarma DR, Patel AG (2013) Rhabdomyolysis in bariatric surgery: a systematic review. Obes Surg 23:1333-1340

85. Poso T, Kesek D, Aroch R et al (2013) Morbid obesity and optimization of preoperative fluid therapy. Obes Surg 23:1799-1805

86. Adams JP, Murphy PG (2000) Obesity in anaesthesia and intensive care. Br J Anaesth 85:91-108

87. Sharma SK, McCauley J, Cottam D et al (2006) Acute changes in renal function after laparoscopic gastric surgery for morbid obesity. Surg Obes Relat Dis 2:389-392

88. Bundgaard-Nielsen M, Secher NH, Kehlet H (2009) 'Liberal' vs. 'restrictive' perioperative fluid therapy-a critical assessment of the evidence. Acta Anaesthesiol Scand 53:843-851

89. Varadhan KK, Lobo DN (2010) A meta-analysis of randomised controlled trials of intravenous fluid therapy in major elective open abdominal surgery: getting the balance right. Proc Nutr Soc 69:488-498 
90. de Menezes Ettinger JE, dos Santos Filho PV, Azaro E et al (2005) Prevention of rhabdomyolysis in bariatric surgery. Obes Surg 15:874-9

91. Domi R, Laho H (2012) Anesthetic challenges in the obese patient. J Anesth 26:758-765

92. Schuster R, Alami RS, Curet MJ et al (2006) Intra-operative fluid volume influences postoperative nausea and vomiting after laparoscopic gastric bypass surgery. Obes Surg 16:848-851

93. Ogunnaike BO, Jones SB, Jones DB et al (2002) Anesthetic considerations for bariatric surgery. Anesth Analg 95:1793-1805

94. Nossaman VE, Richardson WS 3rd, Wooldridge JB Jr et al (2015) Role of intraoperative fluids on hospital length of stay in laparoscopic bariatric surgery: a retrospective study in 224 consecutive patients. Surg Endosc 29:2960-2969

95. Wool DB, Lemmens HJ, Brodsky JB et al (2010) Intraoperative fluid replacement and postoperative creatine phosphokinase levels in laparoscopic bariatric patients. Obes Surg 20:698-701

96. Matot I, Paskaleva R, Eid L et al (2012) Effect of the volume of fluids administered on intraoperative oliguria in laparoscopic bariatric surgery: a randomized controlled trial. Arch Surg 147:228-234

97. Jain AK, Dutta A (2010) Stroke volume variation as a guide to fluid administration in morbidly obese patients undergoing laparoscopic bariatric surgery. Obes Surg 20:709-715

98. Awad S, Carter S, Purkayastha S et al (2014) Enhanced recovery after bariatric surgery (ERABS): clinical outcomes from a tertiary referral bariatric centre. Obes Surg 24(5):753-758

99. Feldheiser A, Aziz O, Baldini G et al (2015) Enhanced recovery after surgery (ERAS) for gastrointestinal surgery, part 2: consensus statement for anaesthesia practice. Acta Anaesthesiol Scand 60(3):289-334

100. Apfel CC, Heidrich FM, Jukar-Rao S et al (2012) Evidencebased analysis of risk factors for postoperative nausea and vomiting. Br J Anaesth 109:742-753

101. Gan TJ, Diemunsch P, Habib AS et al (2014) Consensus guidelines for the management of postoperative nausea and vomiting. Anesth Analg 118:85-113

102. Ziemann-Gimmel P, Goldfarb AA, Koppman J et al (2014) Opioid-free total intravenous anaesthesia reduces postoperative nausea and vomiting in bariatric surgery beyond triple prophylaxis. Br J Anaesth 112:906-911

103. Benevides ML, Oliveira SS, de Aguilar-Nascimento JE (2013) The combination of haloperidol, dexamethasone, and ondansetron for prevention of postoperative nausea and vomiting in laparoscopic sleeve gastrectomy: a randomized double-blind trial. Obes Surg 23:1389-1396

104. Strum EM, Szenohradszki J, Kaufman WA, et al. (2004) Emergence and recovery characteristics of desflurane versus sevoflurane in morbidly obese adult surgical patients: a prospective, randomized study. Anesth Analg 99:1848-1853. table of contents

105. Juvin P, Vadam C, Malek L et al (2000) Postoperative recovery after desflurane, propofol, or isoflurane anesthesia among morbidly obese patients: a prospective, randomized study. Anesth Analg 91:714-719

106. Bilotta F, Doronzio A, Cuzzone V et al (2009) Early postoperative cognitive recovery and gas exchange patterns after balanced anesthesia with sevoflurane or desflurane in overweight and obese patients undergoing craniotomy: a prospective randomized trial. J Neurosurg Anesthesiol 21:207-213

107. Kaur A, Jain AK, Sehgal R et al (2013) Hemodynamics and early recovery characteristics of desflurane versus sevoflurane in bariatric surgery. J Anaesthesiol Clin Pharmacol 29:36-40

108. Apfel CC, Kranke P, Katz MH et al (2002) Volatile anaesthetics may be the main cause of early but not delayed postoperative vomiting: a randomized controlled trial of factorial design. $\mathrm{Br} \mathbf{J}$ Anaesth 88:659-668
109. Cattano D, Killoran PV, Iannucci D et al (2013) Anticipation of the difficult airway: preoperative airway assessment, an educational and quality improvement tool. Br J Anaesth 111:276-285

110. Leoni A, Arlati S, Ghisi D et al (2014) Difficult mask ventilation in obese patients: analysis of predictive factors. Minerva Anestesiol 80:149-157

111. Nicholson A, Cook TM, Smith AF et al (2013) Supraglottic airway devices versus tracheal intubation for airway management during general anaesthesia in obese patients. Cochrane Database Syst Rev 9:CD010105. doi:10.1002/14651858. CD010105.pub2

112. Nicholson A, Smith AF, Lewis SR et al (2014) Tracheal intubation with a flexible intubation scope versus other intubation techniques for obese patients requiring general anaesthesia. Cochrane Database Syst Rev 1:Cd010320

113. Collins JS, Lemmens HJ, Brodsky JB et al (2004) Laryngoscopy and morbid obesity: a comparison of the "sniff" and "ramped" positions. Obes Surg 14:1171-1175

114. Erlandsson K, Odenstedt H, Lundin S et al (2006) Positive endexpiratory pressure optimization using electric impedance tomography in morbidly obese patients during laparoscopic gastric bypass surgery. Acta Anaesthesiol Scand 50:833-839

115. Reinius H, Jonsson L, Gustafsson S et al (2009) Prevention of atelectasis in morbidly obese patients during general anesthesia and paralysis: a computerized tomography study. Anesthesiology 111:979-987

116. Talab HF, Zabani IA, Abdelrahman HS et al (2009) Intraoperative ventilatory strategies for prevention of pulmonary atelectasis in obese patients undergoing laparoscopic bariatric surgery. Anesth Analg 109:1511-1516

117. Whalen FX, Gajic O, Thompson GB et al (2006) The effects of the alveolar recruitment maneuver and positive end-expiratory pressure on arterial oxygenation during laparoscopic bariatric surgery. Anesth Analg 102:298-305

118. Bohm SH, Thamm OC, von Sandersleben A et al (2009) Alveolar recruitment strategy and high positive end-expiratory pressure levels do not affect hemodynamics in morbidly obese intravascular volume-loaded patients. Anesth Analg 109:160-163

119. Aldenkortt M, Lysakowski C, Elia N et al (2012) Ventilation strategies in obese patients undergoing surgery: a quantitative systematic review and meta-analysis. Br J Anaesth 109:493-502

120. Futier E, Constantin JM, Paugam-Burtz C et al (2013) A trial of intraoperative low-tidal-volume ventilation in abdominal surgery. N Engl J Med 369:428-437

121. Dixon BJ, Dixon JB, Carden JR, et al. (2005) Preoxygenation is more effective in the 25 degrees head-up position than in the supine position in severely obese patients: a randomized controlled study. Anesthesiology 102:1110-1115. discussion 5A

122. Valenza F, Vagginelli F, Tiby A et al (2007) Effects of the beach chair position, positive end-expiratory pressure, and pneumoperitoneum on respiratory function in morbidly obese patients during anesthesia and paralysis. Anesthesiology 107:725-732

123. Mulier JP, Dillemans B, Van Cauwenberge S (2010) Impact of the patient's body position on the intraabdominal workspace during laparoscopic surgery. Surg Endosc 24:1398-1402

124. Staehr-Rye AK, Rasmussen LS, Rosenberg J et al (2014) Surgical space conditions during low-pressure laparoscopic cholecystectomy with deep versus moderate neuromuscular blockade: a randomized clinical study. Anesth Analg 119:1084-1092

125. Martini CH, Boon M, Bevers RF et al (2014) Evaluation of surgical conditions during laparoscopic surgery in patients with moderate vs deep neuromuscular block. Br J Anaesth 112:498-505

126. Carron M, Gasparetto M, Vindigni V et al (2014) Laparoscopic surgery in a morbidly obese, high-risk cardiac patient: the 
benefits of deep neuromuscular block and sugammadex. Br J Anaesth 113:186-187

127. Batistaki C, Tentes P, Deligiannidi P et al (2015) Residual neuromuscular blockade in a real life clinical setting. Correlation with sugammadex or neostigmine administration. Minerva Anestesiol [Epub ahead of print]

128. Fortier LP, McKeen D, Turner K et al (2015) The RECITE Study: a Canadian Prospective. Multicenter Study of the Incidence and Severity of Residual Neuromuscular Blockade. Anesth Analg 121:366-372

129. Schreiber JU (2014) Management of neuromuscular blockade in ambulatory patients. Curr Opin Anaesthesiol 27:583-588

130. Ozturk Arikan FG, Turan G, Ozgultekin A et al (2015) Rocuronium: automatic infusion versus manual administration with TOF monitorisation. J Clin Monit Comput. doi:10.1007/ s10877-015-9751-2

131. Murphy GS, Brull SJ (2010) Residual neuromuscular block: lessons unlearned. Part I: definitions, incidence, and adverse physiologic effects of residual neuromuscular block. Anesth Analg 111:120-128

132. Sauer M, Stahn A, Soltesz S et al (2011) The influence of residual neuromuscular block on the incidence of critical respiratory events. A randomised, prospective, placebo-controlled trial. Eur J Anaesthesiol 28:842-848

133. Murphy GS, Szokol JW, Marymont JH et al (2008) Intraoperative acceleromyographic monitoring reduces the risk of residual neuromuscular blockade and adverse respiratory events in the postanesthesia care unit. Anesthesiology 109:389-398

134. Butterly A, Bittner EA, George E et al (2010) Postoperative residual curarization from intermediate-acting neuromuscular blocking agents delays recovery room discharge. Br J Anaesth 105:304-309

135. Murphy GS, Szokol JW, Avram MJ et al (2011) Intraoperative acceleromyography monitoring reduces symptoms of muscle weakness and improves quality of recovery in the early postoperative period. Anesthesiology 115:946-954

136. Abrishami A, Ho J, Wong J, et al. (2009) Sugammadex, a selective reversal medication for preventing postoperative residual neuromuscular blockade. Cochrane Database Syst Rev:Cd007362

137. Suzuki T, Masaki G, Ogawa S (2006) Neostigmine-induced reversal of vecuronium in normal weight, overweight and obese female patients. Br J Anaesth 97:160-163

138. Baillard C, Clec'h C, Catineau J et al (2005) Postoperative residual neuromuscular block: a survey of management. Br $\mathrm{J}$ Anaesth 95:622-626

139. Jones RK, Caldwell JE, Brull SJ et al (2008) Reversal of profound rocuronium-induced blockade with sugammadex: a randomized comparison with neostigmine. Anesthesiology 109:816-824

140. Blobner M, Eriksson LI, Scholz J et al (2010) Reversal of rocuronium-induced neuromuscular blockade with sugammadex compared with neostigmine during sevoflurane anaesthesia: results of a randomised, controlled trial. Eur J Anaesthesiol 27:874-881

141. Nguyen NT, Nguyen B, Shih A et al (2013) Use of laparoscopy in general surgical operations at academic centers. Surg Obes Relat Dis 9:15-20

142. Lujan JA, Frutos MD, Hernandez Q et al (2004) Laparoscopic versus open gastric bypass in the treatment of morbid obesity: a randomized prospective study. Ann Surg 239:433-437

143. Nguyen NT, Goldman C, Rosenquist CJ et al (2001) Laparoscopic versus open gastric bypass: a randomized study of outcomes, quality of life, and costs. Ann Surg 234:279-289. discussion 289-91

144. Westling A, Gustavsson S (2001) Laparoscopic vs open Rouxen-Y gastric bypass: a prospective, randomized trial. Obes Surg 11:284-292
145. Higa KD, Ho T, Boone KB (2003) Internal hernias after laparoscopic Roux-en-Y gastric bypass: incidence, treatment and prevention. Obes Surg 13:350-354

146. Capella RF, Iannace VA, Capella JF (2006) Bowel obstruction after open and laparoscopic gastric bypass surgery for morbid obesity. J Am Coll Surg 203:328-335

147. Sussenbach SP, Silva EN, Pufal MA et al (2014) Systematic review of economic evaluation of laparotomy versus laparoscopy for patients submitted to Roux-en-Y gastric bypass. PLoS ONE 9:e99976

148. Bailey JG, Hayden JA, Davis PJ et al (2014) Robotic versus laparoscopic Roux-en-Y gastric bypass (RYGB) in obese adults ages 18 to 65 years: a systematic review and economic analysis. Surg Endosc 28:414-426

149. Nelson R, Edwards S, Tse B (2005) Prophylactic nasogastric decompression after abdominal surgery. Cochrane Database Syst Rev:Cd004929

150. Huerta S, Arteaga JR, Sawicki MP et al (2002) Assessment of routine elimination of postoperative nasogastric decompression after Roux-en-Y gastric bypass. Surgery 132:844-848

151. Yang Z, Zheng Q, Wang Z (2008) Meta-analysis of the need for nasogastric or nasojejunal decompression after gastrectomy for gastric cancer. Br J Surg 95:809-816

152. Liscia G, Scaringi S, Facchiano E et al (2014) The role of drainage after Roux-en-Y gastric bypass for morbid obesity: a systematic review. Surg Obes Relat Dis 10:171-176

153. Kavuturu S, Rogers AM, Haluck RS (2012) Routine drain placement in Roux-en- $Y$ gastric bypass: an expanded retrospective comparative study of 755 patients and review of the literature. Obes Surg 22:177-181

154. Kim J, Lee J, Hyung WJ et al (2004) Gastric cancer surgery without drains: a prospective randomized trial. J Gastrointest Surg 8:727-732

155. Petrowsky H, Demartines N, Rousson V, et al. (2004) Evidencebased value of prophylactic drainage in gastrointestinal surgery: a systematic review and meta-analyses. Ann Surg 240:1074-1084. discussion 1084-5

156. Siyam M, Benhamou D (2007) Anaesthetic management of adult patients with obstructive sleep apnea syndrome. Ann Fr Anesth Reanim 26:39-52

157. Ziemann-Gimmel P, Hensel P, Koppman J et al (2013) Multimodal analgesia reduces narcotic requirements and antiemetic rescue medication in laparoscopic Roux-en-Y gastric bypass surgery. Surg Obes Relat Dis 9:975-980

158. Maund E, McDaid C, Rice S et al (2011) Paracetamol and selective and non-selective non-steroidal anti-inflammatory drugs for the reduction in morphine-related side-effects after major surgery: a systematic review. $\mathrm{Br} \mathrm{J}$ Anaesth 106:292-297

159. Chaparro LE, Clarke H, Valdes PA et al (2012) Adding pregabalin to a multimodal analgesic regimen does not reduce pain scores following cosmetic surgery: a randomized trial. J Anesth 26:829-835

160. Tufanogullari B, White PF, Peixoto MP et al (2008) Dexmedetomidine infusion during laparoscopic bariatric surgery: the effect on recovery outcome variables. Anesth Analg 106:1741-1748

161. Graves DA, Batenhorst RL, Bennett RL et al (1983) Morphine requirements using patient-controlled analgesia: influence of diurnal variation and morbid obesity. Clin Pharm 2:49-53

162. Frey WC, Pilcher J (2003) Obstructive sleep-related breathing disorders in patients evaluated for bariatric surgery. Obes Surg 13:676-683

163. Beaussier M, Bouaziz H, Aubrun F et al (2012) Wound infiltration with local anesthetics for postoperative analgesia. Results of a national survey about its practice in France. Ann Fr Anesth Reanim 31:120-125 
164. Kahokehr A, Sammour T, Soop M et al (2010) Intraperitoneal use of local anesthetic in laparoscopic cholecystectomy: systematic review and metaanalysis of randomized controlled trials. J Hepatobiliary Pancreat Sci 17:637-656

165. Pappas-Gogos G, Tsimogiannis KE, Zikos N et al (2008) Preincisional and intraperitoneal ropivacaine plus normal saline infusion for postoperative pain relief after laparoscopic cholecystectomy: a randomized double-blind controlled trial. Surg Endosc 22:2036-2045

166. Alkhamesi NA, Kane JM, Guske PJ et al (2008) Intraperitoneal aerosolization of bupivacaine is a safe and effective method in controlling postoperative pain in laparoscopic Roux-en-Y gastric bypass. J Pain Res 1:9-13

167. Hilvering B, Draaisma WA, van der Bilt JD et al (2011) Randomized clinical trial of combined preincisional infiltration and intraperitoneal instillation of levobupivacaine for postoperative pain after laparoscopic cholecystectomy. Br J Surg 98:784-789

168. Wassef M, Lee DY, Levine JL et al (2013) Feasibility and analgesic efficacy of the transversus abdominis plane block after single-port laparoscopy in patients having bariatric surgery. J Pain Res 6:837-841

169. von Ungern-Sternberg BS, Regli A, Reber A et al (2005) Effect of obesity and thoracic epidural analgesia on perioperative spirometry. Br J Anaesth 94:121-127

170. Levy BF, Scott MJ, Fawcett W et al (2011) Randomized clinical trial of epidural, spinal or patient-controlled analgesia for patients undergoing laparoscopic colorectal surgery. Br J Surg 98:1068-1078

171. Charghi R, Backman S, Christou N et al (2003) Patient controlled i.v. analgesia is an acceptable pain management strategy in morbidly obese patients undergoing gastric bypass surgery. A retrospective comparison with epidural analgesia. Can J Anaesth 50:672-678

172. Mismetti P, Laporte S, Darmon JY et al (2001) Meta-analysis of low molecular weight heparin in the prevention of venous thromboembolism in general surgery. Br J Surg 88:913-930

173. Clagett GP, Reisch JS (1988) Prevention of venous thromboembolism in general surgical patients. Results of meta-analysis. Ann Surg 208:227-240

174. Overby DW, Kohn GP, Cahan MA et al (2009) Prevalence of thrombophilias in patients presenting for bariatric surgery. Obes Surg 19:1278-1285

175. Samama MM (2000) An epidemiologic study of risk factors for deep vein thrombosis in medical outpatients: the Sirius study. Arch Intern Med 160:3415-3420

176. Geerts WH, Pineo GF, Heit JA et al (2004) Prevention of venous thromboembolism: the Seventh ACCP Conference on Antithrombotic and Thrombolytic Therapy. Chest 126:338s-400s

177. Gonzalez QH, Tishler DS, Plata-Munoz JJ et al (2004) Incidence of clinically evident deep venous thrombosis after laparoscopic Roux-en-Y gastric bypass. Surg Endosc 18:1082-1084

178. Guyatt GH, Akl EA, Crowther M et al (2012) Executive summary: antithrombotic therapy and prevention of thrombosis, 9th ed: American college of chest physicians evidence-based clinical practice guidelines. Chest 141:7S-47S

179. Shepherd MF, Rosborough TK, Schwartz ML (2003) Heparin thromboprophylaxis in gastric bypass surgery. Obes Surg 13:249-253

180. Hirsh J, Raschke R (2004) Heparin and low-molecular-weight heparin: the Seventh ACCP Conference on Antithrombotic and Thrombolytic Therapy. Chest 126:188s-203s

181. American Society for Metabolic and Bariatric Surgery Clinical Issues Committee (2013) ASMBS updated position statement on prophylactic measures to reduce the risk of venous thromboembolism in bariatric surgery patients. Surg Obes Relat Dis 9:493-497
182. Rowan BO, Kuhl DA, Lee MD et al (2008) Anti-Xa levels in bariatric surgery patients receiving prophylactic enoxaparin. Obes Surg 18:162-166

183. Simone EP, Madan AK, Tichansky DS et al (2008) Comparison of two low-molecular-weight heparin dosing regimens for patients undergoing laparoscopic bariatric surgery. Surg Endosc 22:2392-2395

184. Borkgren-Okonek MJ, Hart RW, Pantano JE et al (2008) Enoxaparin thromboprophylaxis in gastric bypass patients: extended duration, dose stratification, and antifactor Xa activity. Surg Obes Relat Dis 4:625-631

185. Bergqvist D, Agnelli G, Cohen AT et al (2002) Duration of prophylaxis against venous thromboembolism with enoxaparin after surgery for cancer. N Engl J Med 346:975-980

186. Hull RD, Pineo GF, Stein PD et al (2001) Extended out-ofhospital low-molecular-weight heparin prophylaxis against deep venous thrombosis in patients after elective hip arthroplasty: a systematic review. Ann Intern Med 135:858-869

187. Lorch H, Zwaan M, Siemens HJ et al (2000) Temporary vena cava filters and ultrahigh streptokinase thrombolysis therapy: a clinical study. Cardiovasc Intervent Radiol 23:273-278

188. Kaufman JA, Kinney TB, Streiff MB et al (2006) Guidelines for the use of retrievable and convertible vena cava filters: report from the Society of Interventional Radiology multidisciplinary consensus conference. Surg Obes Relat Dis 2:200-212

189. Offner PJ, Hawkes A, Madayag R et al (2003) The role of temporary inferior vena cava filters in critically ill surgical patients. Arch Surg 138:591-594. discussion 594-5

190. Mechanick JI, Kushner RF, Sugerman HJ et al (2008) American Association of Clinical Endocrinologists. The Obesity Society, and American Society for Metabolic \& Bariatric Surgery Medical guidelines for clinical practice for the perioperative nutritional, metabolic, and nonsurgical support of the bariatric surgery patient. Endocr Pract 14(Suppl 1):1-83

191. Crowley LV, Seay J, Mullin G (1984) Late effects of gastric bypass for obesity. Am J Gastroenterol 79:850-860

192. Kushner R (2000) Managing the obese patient after bariatric surgery: a case report of severe malnutrition and review of the literature. JPEN J Parenter Enteral Nutr 24:126-132

193. Stocker DJ (2003) Management of the bariatric surgery patient. Endocrinol Metab Clin North Am 32:437-457

194. Brolin RE (2001) Gastric bypass. Surg Clin North Am 81:1077-1095

195. Heber D, Greenway FL, Kaplan LM et al (2010) Endocrine and nutritional management of the post-bariatric surgery patient: an Endocrine Society Clinical Practice Guideline. J Clin Endocrinol Metab 95:4823-4843

196. Donadelli SP, Junqueira-Franco MV, de Mattos Donadelli CA et al (2012) Daily vitamin supplementation and hypovitaminosis after obesity surgery. Nutrition 28:391-396

197. Khanna V, Kashyap SR (2015) Clinical management of type 2 diabetes mellitus after bariatric surgery. Curr Atheroscler Rep 17:59

198. Expert Panel on Detection, Evaluation, and Treatment of High Blood Cholesterol in Adults (2001) Executive summary of the third report of the national cholesterol education program (NCEP) expert panel on detection, evaluation, and treatment of high blood cholesterol in adults (adult treatment panel III). JAMA 285:2486-2497

199. The Evidence Report. National Institutes of Health (1998) Clinical guidelines on the identification, evaluation, and treatment of overweight and obesity in adults - the evidence report. National Institutes of Health. Obes Res 6(Suppl 2):51s-209s

200. Dhatariya K, Levy N, Kilvert A et al (2012) NHS Diabetes guideline for the perioperative management of the adult patient with diabetes. Diabet Med 29:420-433 
201. Robinson PD (2014) Obesity and its impact on the respiratory system. Paediatr Respir Rev 15:219-226

202. Eichenberger A, Proietti S, Wicky S et al (2002) Morbid obesity and postoperative pulmonary atelectasis: an underestimated problem. Anesth Analg 95:1788-1792. table of contents

203. Guimaraes MM, El Dib R, Smith AF et al (2009) Incentive spirometry for prevention of postoperative pulmonary complications in upper abdominal surgery. Cochrane Database Syst Rev:Cd006058

204. von Ungern-Sternberg BS, Regli A, Schneider MC et al (2004) Effect of obesity and site of surgery on perioperative lung volumes. Br J Anaesth 92:202-207

205. Fleischmann E, Kurz A, Niedermayr M et al (2005) Tissue oxygenation in obese and non-obese patients during laparoscopy. Obes Surg 15:813-819

206. Chung F, Subramanyam R, Liao P et al (2012) High STOP-Bang score indicates a high probability of obstructive sleep apnoea. $\mathrm{Br}$ J Anaesth 108:768-775

207. Ahmad S, Nagle A, McCarthy RJ et al (2008) Postoperative hypoxemia in morbidly obese patients with and without obstructive sleep apnea undergoing laparoscopic bariatric surgery. Anesth Analg 107:138-143

208. Mehta V, Vasu TS, Phillips B et al (2013) Obstructive sleep apnea and oxygen therapy: a systematic review of the literature and meta-analysis. J Clin Sleep Med 9:271-279

209. Meoli AL, Rosen CL, Kristo D et al (2003) Upper airway management of the adult patient with obstructive sleep apnea in the perioperative period-avoiding complications. Sleep 26:1060-1065

210. Wong DT, Adly E, Ip HY et al (2011) A comparison between the Boussignac continuous positive airway pressure mask and the venturi mask in terms of improvement in the $\mathrm{PaO} 2 / \mathrm{F}(\mathrm{I}) \mathrm{O} 2$ ratio in morbidly obese patients undergoing bariatric surgery: a randomized controlled trial. Can J Anaesth 58:532-539

211. Giles TL, Lasserson TJ, Smith BJ et al (2006) Continuous positive airways pressure for obstructive sleep apnoea in adults. Cochrane Database Syst Rev:Cd001106

212. Goudra BG, Singh PM, Penugonda LC et al (2014) Significantly reduced hypoxemic events in morbidly obese patients undergoing gastrointestinal endoscopy: predictors and practice effect. J Anaesthesiol Clin Pharmacol 30:71-77

213. Neligan PJ, Malhotra G, Fraser M et al (2009) Continuous positive airway pressure via the Boussignac system immediately after extubation improves lung function in morbidly obese patients with obstructive sleep apnea undergoing laparoscopic bariatric surgery. Anesthesiology 110:878-884

214. Helling TS, Willoughby TL, Maxfield DM et al (2004) Determinants of the need for intensive care and prolonged mechanical ventilation in patients undergoing bariatric surgery. Obes Surg 14:1036-1041

215. Grover BT, Priem DM, Mathiason MA et al (2010) Intensive care unit stay not required for patients with obstructive sleep apnea after laparoscopic Roux-en-Y gastric bypass. Surg Obes Relat Dis 6:165-170

216. Singh M, Liao P, Kobah S et al (2013) Proportion of surgical patients with undiagnosed obstructive sleep apnoea. $\mathrm{Br} \mathrm{J}$ Anaesth 110:629-636
217. Mutter TC, Chateau D, Moffatt M et al (2014) A matched cohort study of postoperative outcomes in obstructive sleep apnea: could preoperative diagnosis and treatment prevent complications? Anesthesiology 121:707-718

218. Zarbock A, Mueller E, Netzer S et al (2009) Prophylactic nasal continuous positive airway pressure following cardiac surgery protects from postoperative pulmonary complications: a prospective, randomized, controlled trial in 500 patients. Chest $135: 1252-1259$

219. Komatsu R, Turan AM, Orhan-Sungur M et al (2007) Remifentanil for general anaesthesia: a systematic review. Anaesthesia 62:1266-1280

220. Olbers T, Fagevik-Olsen M, Maleckas A et al (2005) Randomized clinical trial of laparoscopic Roux-en-Y gastric bypass versus laparoscopic vertical banded gastroplasty for obesity. $\mathrm{Br}$ J Surg 92:557-562

221. Jensen C, Tejirian T, Lewis C et al (2008) Postoperative CPAP and BiPAP use can be safely omitted after laparoscopic Rouxen-Y gastric bypass. Surg Obes Relat Dis 4:512-514

222. Lindberg E, Berne C, Elmasry A et al (2006) CPAP treatment of a population-based sample-what are the benefits and the treatment compliance? Sleep Med 7:553-560

223. Liao P, Yegneswaran B, Vairavanathan S et al (2009) Postoperative complications in patients with obstructive sleep apnea: a retrospective matched cohort study. Can J Anaesth 56:819-828

224. Bolden N, Smith CE, Auckley D et al (2007) Perioperative complications during use of an obstructive sleep apnea protocol following surgery and anesthesia. Anesth Analg 105:1869-1870

225. DeMaria EJ, Portenier D, Wolfe L (2007) Obesity surgery mortality risk score: proposal for a clinically useful score to predict mortality risk in patients undergoing gastric bypass. Surg Obes Relat Dis 3:134-140

226. Macintyre PE, Loadsman JA, Scott DA (2011) Opioids, ventilation and acute pain management. Anaesth Intensive Care 39:545-558

227. Rennotte MT, Baele P, Aubert G et al (1995) Nasal continuous positive airway pressure in the perioperative management of patients with obstructive sleep apnea submitted to surgery. Chest 107:367-374

228. Roulin D, Donadini A, Gander S et al (2013) Cost-effectiveness of the implementation of an enhanced recovery protocol for colorectal surgery. Br J Surg 100:1108-1114

229. Joliat GR, Labgaa I, Petermann D et al (2015) Cost-benefit analysis of an enhanced recovery protocol for pancreaticoduodenectomy. Br J Surg 102:1676-1683

230. King PM, Blazeby JM, Ewings P et al (2006) The influence of an enhanced recovery programme on clinical outcomes, costs and quality of life after surgery for colorectal cancer. Colorectal Dis 8:506-513

231. Vlug MS, Wind J, Hollmann MW et al (2011) Laparoscopy in combination with fast track multimodal management is the best perioperative strategy in patients undergoing colonic surgery: a randomized clinical trial (LAFA-study). Ann Surg 254:868-875 